\title{
Pricing of time-varying illiquidity within the Eurozone: Evidence using a Markov switching liquidity-adjusted capital asset pricing model ${ }^{\text {ir }}$
}

\author{
Stefano Grillini a, Aydin Ozkan ${ }^{\text {b }}$, Abhijit Sharma ${ }^{\text {a, }}$, Mazin A.M. Al Janabi ${ }^{\text {c }}$ \\ ${ }^{a}$ University of Bradford School of Management, Emm Lane, Bradford, BD9 4JL, UK \\ ${ }^{\mathrm{b}}$ University of Huddersfield Business School, UK \\ ${ }^{\text {c }}$ EGADE Business School, Tecnologico de Monterrey, Mexico
}

\begin{abstract}
A B S T R A C T
This paper investigates time-varying characteristics of illiquidity and the pricing of its risk using a liquidity-adjusted capital asset pricing model (L-CAPM). Collecting data from a pool of Eurozone countries between 1990 and 2018, we employ Markov switching models to assess the degree of persistence of illiquidity shocks. Contrary to prior research, which largely makes use of autoregressive (AR) processes, we provide strong evidence that illiquidity is time-varying and the persistence of shocks determines two distinct regimes characterised by high and low illiquidity. We assess pricing of illiquidity risk by developing and empirically testing a conditional L-CAPM model, where different regimes constitute priced risk factors for the cross-section of stock returns. We extend previous unconditional versions of L-CAPM models and we show that the various channels through which illiquidity affects asset returns and price of risks are time-varying. We find strong support for our conditional L-CAPM and our results are robust to alternative specifications and estimation techniques. These findings have important implications for portfolio management practices and are relevant to portfolio and risk managers and regulatory institutions.
\end{abstract}

\section{Introduction}

Stock market illiquidity and its time-varying characteristics, including consideration of pricing of illiquidity risk, have become increasingly important for researchers and finance industry professionals, following the global financial crisis (GFC) of 2007-2009. Sudden and significant falls in liquidity are shown to be key causal factors affecting intertemporal changes in liquidity. For instance, (Amihud, Mendelson, \& Wood, 1990; Roll, 1988) attribute the market crash seen on the $19^{\text {th }}$ of October 1987 to a widespread temporary reduction in liquidity. A further noteworthy example is the default of the Long Term Capital Management (LTCM) fund, which is linked to a sudden shortage in liquidity (Brunnermeier \& Pedersen, 2009). The collapse of LTCM was mainly due to an excessive exposure to liquidity risk, even though market risk was hedged. There are two implications that follow from these observations. First, liquidity shocks are persistent, as in the GFC. Second, both retail and institutional investors should adequately account for liquidity risk in the formation of their portfolios. This

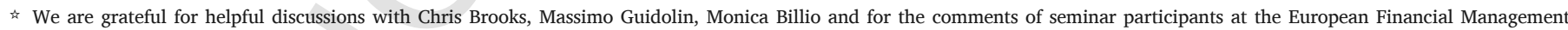
Association annual conference 2018 and EcoMod Annual Conference 2018. We are responsible for all remaining errors.

* Corresponding author.

Email address: a.sharma12@bradford.ac.uk (A. Sharma) 
paper addresses both of these key issues, namely the persistence of illiquidity shocks and its effects on the pricing of illiquidity risk.

There are a large number of studies in the market microstructure literature, which consider pricing of liquidity risk. From an initial asset-specific focus (Amihud \& Mendelson, 1986) to a subsequent market-wide perspective (Acharya \& Pedersen, 2005; Amihud, Hameed, Kang, \& Zhang, 2015; Brockman, Chung, \& Pérignon, 2009; Chordia, Roll, \& Subrahmanyam, 2000), prior research investigates liquidity both as an attribute and as a priced risk factor. Given the repeated examples of financial crises and market turmoil, illiquidity continues to be of significant interest to both investors and researchers. Nevertheless, both persistence of illiquidity shocks and the effects of these shocks on the pricing of illiquidity risk remain largely unexplored. ${ }^{1}$ The issues that are of interest relate to the use of suitable econometric techniques to adequately model persistent shocks and analyse their effects on portfolios held by investors. We investigate these aspects of illiquidity, focusing on the following research questions: (i) Are illiquidity shocks persistent? (ii) What are the implications of persistent illiquidity shocks within the cross-section of stock returns? (iii) Is the illiquidity risk premium time-varying and dependent on illiquidity shocks?

While the time-varying characteristic of illiquidity has been widely studied, existing econometric models largely fail to adequately account for this important attribute. Within the current literature, illiquidity time-series are predominantly modelled by using autoregressive (AR) processes (Amihud, 2002; Korajczyk \& Sadka, 2008). However, such models involve very restrictive econometric assumptions such as residuals being Gaussian and temporary. It is also often implicitly assumed that structural breaks do notexist. They are appropriate for representing the time series nature of liquidity during tranquil periods. However, they fail to capture important features of illiquidity during periods of greater uncertainty and financial turmoil, when shocks become morepersistent and markets exhibit prolonged periods of illiquidity. Brunnermeier and Pedersen (2009) describe this mechanism as a liquidity spiral, whereby a shock in market liquidity causes higher margin requirements from liquidity providers with the effect of reducing overall market liquidity even further.

Our first contribution relates to the modelling of illiquidity time-series. We employ a non-linear technique, using Markov regime switching (MRS) models, which accounts for the effects of persistent illiquidity shocks and overcomes key econometric limitations of AR(p) processes. In fact, illiquidity time-series, likewise other financial series, are often characterised by fat tails, non-linearities, serial correlation, non-stationarity and ARCH effects (Bollerslev, 1986). It is known that the MRS approach captures better some of

1 The terms liquidity and illiquidity are used interchangeably throughout the paper, where high liquidity corresponds to low illiquidity and vice-versa. the stylized facts of financial series such as heavy tails, asymmetry and time-varying parameters. We investigate the time-series behaviour of illiquidity across stock markets spanning seven Eurozone countries that include both core and peripheral economies. We first test a two state Markov model on a time-series of illiquidity. Following Watanabe and Watanabe (2008), we interpret the two regimes as periods of high and low illiquidity. We find strong evidence for two regimes within our illiquidity time-series. Our diagnostics show reduced autocorrelation within the residuals, indicating a tendency towards the Gaussian distribution, as compared to AR(1) estimations. We find that shocks are persistent and they determine distinct states of illiquidity, supporting the notion of liquidity spirals.

Our second important contribution emerges from our empirical approach in investigating the pricing of illiquidity regimes. Specifically, we develop a liquidity-adjusted CAPM (L-CAPM) model in which risk betas and risk premia change over time conditionally to an unobserved state variable that switches regime with a certain probability. We thus implement a conditional version of the L-CAPM, originally proposed by Acharya and Pedersen (2005) who show that security returns are cross-sectionally dependent on market risk and other three risk betas that capture different facets of liquidity. A similar approach can also be found in Lee (2011), who provides evidence on liquidity risk pricing at a global level. However, with the exception of these two studies, not much has been done with respect to pricing different sources of liquidity risk (see Papavassiliou, 2013 for a discussion).

Starting from the unconditional model proposed by Acharya and Pedersen (2005) and Lee (2011), we extend it further to implement a conditional L-CAPM, where time-varying risk and risk premia are obtained using regime-dependent conditional covariances. In the unconditional L-CAPM model, risk premia are time-invariant, resulting in period of high illiquidity modelled as a series of negative shocks. In contrast, in our conditional L-CAPM model, investors update their expectations based on the currently available information in that shocks are modelled conditional on the contemporaneous regimes of illiquidity and returns. Therefore, risk premia vary conditionally based on the state of the market, reflecting updated beliefs about future illiquidity and the pricing of unexpected shocks, which is an important feature, not captured in the standard unconditional versions.

Our paper also extends the existing literature on Markov switching models (MSM) within a CAPM framework, by including time-varying risk premia for three measures of liquidity risk. To estimate the time-varying risk premia, we construct state-dependent betas, using regime-specific conditional covariances of innovations in illiquidity and returns. We then estimate two market models of portfolio returns for each country. In the first one, regressors are constituted by risk betas obtained as probability-weighted averages of the unobserved variable being in high or low regimes. In the second model, each risk measure is split into the two regimes, without probability-weighting. This allows us to estimate how each risk 
premium changes according to the state of the market. This study is the first to provide a conditional version of the L-CAPM using regime-specific innovations.

A similar study to ours is that of Watanabe and Watanabe (2008), who link time-varying liquidity betas to changes in investors' preference uncertainty, i.e. incomplete information regarding preferences of other trading counterparts. However, they exclude market risk from the estimation and they use a single measure to capture all aspects of liquidity risk. In contrast, we compute regime-dependent betas after the pre-estimation of MSM on the illiquidity time series and we account for three different sources of liquidity risk. Using a number of appropriate estimation methods, including the (Fama \& MacBeth, 1973) OLS procedure, we find strong evidence indicating that pricing of liquidity risk is conditional on each regime. In particular, in line with past research (e.g., Amihud, 2002), we observe a negative effect of unexpected conditional illiquidity shocks on contemporaneous stock returns. We also find that both regimes are significantly priced and that illiquidity risk absorbs that part of market risk, which is found to have a negative premium in most of our results. ${ }^{2}$ Our analysis yields a particularly relevant premium for covariance between portfolio returns and market illiquidity, indicating that investors require a premium for holding illiquid stocks during bear markets. This result is well in line with prior research indicating that illiquid stocks provide greater expected future returns (Amihud \& Mendelson, 1986). Our findings are also consistent with the form of liquidity risk described by Pástor and Stambaugh (2003) and with Chordia et al. (2000) who argue that liquidity affects asset pricing through two potential channels: one static, influencing average trading cost and one dynamic that impacts on risk. Our paper makes a further contribution by estimating regime-dependent risk premia and by providing evidence of flight to liquidity. For instance, we observe that the risk premium due to commonality (Chordia et al., 2000) increases with high illiquidity, meaning that investors prefer switching to more liquid securities during persistent periods of high illiquidity. We assess the robustness of our findings applying GMM estimation, as well as alternative specifications, such as pooled OLS within a panel data framework. These empirical findings have important implications to portfolio management practices and may appeal to risk managers, portfolio managers and regulatory agencies in wake of the repercussions of the 2007-2009 GFC. Portfolio managers are increasingly interested in managing liquidity risk, specifically the downside risk associated with liquidity exposure (e.g., Al Janabi, Hernandez, Berger, \& Nguyen, 2017).

The rest of the paper is organised as follows. Section 2 reviews the existing literature and formulates the hypotheses. Section 3 explains our methodology and Section 4 describes the data. The last two

2 Similar apparently counter intuitive findings are also reported in Acharya and Pedersen (2005). sections report our empirical analysis and concluding remarks, respectively.

\section{Literature review and hypotheses development}

An ample microstructure related literature covering liquidity in asset pricing has emerged over the last few decades. The importance of this literature has increased with major market downturns, such as the financial crisis of 2007-2009. It is well known that optimal inventory levels held by market makers are not static (Amihud, 2002), but adjusted according to the speed and likelihood of finding a counterpart for the order flow (Amihud \& Mendelson, 1986). However, liquidity risk is not simply affected by stock-specific characteristics, but also by market-wide shocks (Chordia et al., 2000) that potentially spread during market downturns (Brunnermeier \& Pedersen, 2009). The persistence of these shocks and the effect on securities' returns has not been adequately investigated.

Amihud (2002) provides empirical evidence that illiquidity is persistent and characterised by temporary unexpected shocks using a trade impact measure defined as $\lambda$ in (Kyle, 1985), which captures the level of a stock's illiquidity. Kyle (1985) finds that illiquidity is highly persistent and assumes that shocks represent changes in overall market liquidity relative to investors' expectations. Amihud (2002) employs an AR(1) process, which implies a unique state of illiquidity, as well as unexpected and temporary shocks that are assumed to be white noise. Similar methodologies are employed by Foran and Hutchinson (2015) and Korajczyk and Sadka (2008). They estimate an AR(2) process on pre-whitened extracted principal components for several liquidity measures, providing consistent results with Amihud (2002). Chordia et al. (2000) point to two channels, static and dynamic, through which liquidity affects asset pricing. The static channel influences average trading cost and gives the anticipated co-movement with the market, while the dynamic channel includes unexpected liquidity shocks and influences risk. However, the dynamic channel may be characterised by persistent liquidity shocks caused by liquidity spirals with significant implications for asset returns. Liquidity spirals (Brunnermeier \& Pedersen, 2009) refer to the emergence of liquidity crises from the interaction of market and funding liquidity, where the latter is a characteristic of both securities and agents that trade.

A security is considered to have good funding liquidity if it is easy to borrow using the same security as collateral. An agent has good funding liquidity if she has plenty of capital or has considerable access to financing with low margin requirements. When significant funding liquidity is available, market makers can satisfy even large orders with low margins and thereby increase overall liquidity. This creates a positive effect on market liquidity due to favourable funding conditions. However, liquidity spirals work in reverse during market downturns and this interaction is potentially more violent during such episodes (Brunnermeier \& Pedersen, 2009). When funding liquidity is constrained, market makers reduce liquidity and increase transaction costs, which cause liquidity 
to dry up even further. These dynamics were also at play during the GFC of 2007-2009 and provide a solid theoretical foundation for the persistence of liquidity shocks. Given this background, we test the following hypothesis:

\subsection{Illiquidity shocks are persistent and determine a new state of illiquidity}

The persistence of shocks has natural implications for the pricing of liquidity risk. Since the initial evidence that illiquid stocks provide greater expected future returns (Amihud \& Mendelson, 1986), several authors attempt to incorporate liquidity risk within the standard CAPM (Acharya \& Pedersen, 2005; Jacoby, Fowler, \& Gottesman, 2000; Pástor \& Stambaugh, 2003). Pástor and Stambaugh (2003) observe that stock returns are related cross-sectionally to their sensitivities to innovations in market liquidity (see also Chordia et al., 2000). Acharya and Pedersen (2005) provide supporting evidence of liquidity risk being a priced risk factor employing three liquidity betas that capture different forms of liquidity risk. Further replications and enhancements of the Acharya and Pedersen (2005) model subsequently emerge (see, for example, He \& Kryzanowski, 2006; Lee, 2011; Liu, 2006; Liu, Luo, \& Zhao, 2016; Vu, Chai, \& Do, 2015). Liu (2006) employs a two factor CAPM for the US that includes liquidity, finding that his model better explains the cross-section of stock returns as compared to the standard CAPM or the three-factor model (Fama \& French, 1993). Lee (2011) finds that a security's required rate of return depends on the covariance of its own liquidity with aggregate local and global market liquidity. More recently, Amihud et al. (2015) report international evidence on pricing of illiquidity risk, finding that illiquidity return premia co-vary positively with global and regional illiquidity premia.

The main issue with existing L-CAPM models is that they only capture average liquidity risk but fail to account for the persistence of innovations in aggregate liquidity, i.e. persistence of shocks. Minović and Živković (2014) attempt to capture time-varying liquidity risk premia, by including time dummies that arbitrarily coincide with the most noteworthy events. However, shocks can be endogenous or they can originate from exogenous spillovers (e.g. Andrikopoulos, Angelidis, \& Skintzi, 2014; Forbes \& Rigobon, 2002; Smimou \& Khallouli, 2015) and are thus not easily identifiable with predetermined time-windows. Consequently, a failure to account for persistent liquidity shocks results in an overestimation (underestimation) of liquidity risk in tranquil (turbulent) periods of financial markets. We attempt to fill this gap by explicitly analysing the existence and impact of time-varying illiquidity risk. We test the following hypotheses:

2.2. $H_{0}$ : Liquidity risk is a priced risk factor that does not change over time

$\mathbf{H}_{1}$. : Liquidity risk is a priced risk factor that varies with the state of the market.

\section{Methodology}

\subsection{The illiquidity measure}

Several studies (e.g. Goyenko, Holden, \& Trzcinka, 2009) claim that liquidity is not an observable variable, but rather several measures exist as a proxy for it, which are mostly based on bid and ask prices and volumes. In our analysis, we use the price impact measure proposed by Amihud (2002) which captures the response of price to order flow through the absolute price change per dollar of trading volume. Algebraically, the daily illiquidity measure (ILL) for each stock $i$ in each market $s$ at time $t$ is given by:

$$
I L L I Q_{i, s, t}=\frac{\left|r_{i, s, t}\right|}{V O L_{i, s, t}}
$$

where $r_{i, s, t}$ is the $\log$ return of stock $i$ in market $s$ at day $t$ and $V O L_{i}$, $s, t$ is the volume of stock $i$ in market $s$ at day $t$. Since its introduction, ILLIQ has become extremely popular and widely employed in a large number of empirical studies (see, e.g. Amihud et al., 2015; Watanabe \& Watanabe, 2008). We employ this particular measure as direct proxies based on bid and ask prices are rarely available for large datasets and/ or long time periods, which is far from ideal for studying the effects of illiquidity on expected returns. The Amihud (2002) ILLIQ measure continues to receive strong support with respect to its ability to reasonably accurately measure illiquidity (see Goyenko et al., 2009). We use ILLIQ as in Acharya and Pedersen (2005), which allows us to achieve high levels of comparability between their time-invariant unconditional model and our new conditional L-CAPM model. Using the daily stock-specific illiquidity measure, defined in equation1, we derive the monthly market illiquidity for each market, which is defined as the equally weighted average of single stocks in the market for each month. This procedure is standard in the literature (see, for instance Amihud, 2002; Brockman et al., 2009). Algebraically, the monthly illiquidity measure for each stock is calculated as:

$\operatorname{ILLIQM}_{i, s, m, t}=\frac{1}{D_{i, m}} \sum_{t=1}^{D_{i, m}} \frac{\left|r_{i, s, m, t}\right|}{V O L_{i, s, m, t}}$

where the subscript $m$ indicates the month for which the average is calculated for each stock, while $D_{i, m}$ is the total number of days for each stock in each month. Thereafter, all these stock-specific monthly measures are averaged across all the stocks in each market so that average illiquidity (AILLIQ) is defined as:

$\operatorname{AILLIQ}_{s, m}=\frac{1}{N_{m}} \sum_{i=1}^{N_{m}} \operatorname{ILLIQM_{i,s,m}}$

where $N_{m}$ is the number of stocks in each month in each market. In a similar vein to Acharya and Pedersen (2005) and Amihud (2002), we perform our empirical analysis using monthly observations, for 
several reasons. First, it is argued that in employing MRS models it is conventional to use monthly frequencies to allow a sufficiently long time-series for empirical estimations (Guidolin, 2011). In fact, annual data would reduce the number of available observations, reducing the precision of the estimators. Second, liquidity is a relevant phenomenon predominantly in the short term, therefore hardly captured by annual data. Lastly, Goyenko et al. (2009) show that, within the context of liquidity time-series, the use of lower frequency data (e.g. weekly or monthly) can be useful for estimating high-frequency measures, which suggests the use of high-frequency data is not appropriate either owing to econometric limitations.

\subsection{Time-varying illiquidity}

Liquidity is a persistent phenomenon that characterises financial markets. However, there are also observed pervasive and unexpected liquidity drops with lasting effects on both financial and real economies. In normal conditions liquidity shocks are absorbed by financial intermediaries, but in periods of adverse economic conditions and financial stress, intermediaries become more capital constrained, thus further hampering market liquidity (Brunnermeier \& Pedersen, 2009). Given the existence of volatility clustering and liquidity spirals, it is important to test for the presence of persistent periods of high and low illiquidity in the market. We test whether an endogenous or exogenous shock explains consequent illiquidity effects for a certain period of time.

One of the key properties of time-series to be approached using linear modelling techniques is stationarity. This implies that persistence is captured by constant parameters for the entire time-series and illiquidity shocks are assumed to be distributed as white noise. Amihud (2002) analyses the time series effects of illiquidity on stock returns, finding that expected illiquidity has a positive impact on expected stock returns, while unexpected illiquidity has a negative effect on contemporaneous unexpected stock returns. He models illiquidity time-series as an AR(1) process of the form:

$\ln A I L L I Q_{s, m}=c_{0}+c_{1} \ln A I L L I Q_{s, m-1}+v_{m}$

where $\ln A I L L I Q_{s, m}$ is the natural logarithm of monthly market illiquidity for market $s$ in month $m, c_{0}$ and $c_{1}$ represent the coefficients and $v_{m}$ is the residual. Individuals expect $c_{1}$ to be positive, since it indicates that the current level of illiquidity is based on its past value (one-period expectation), and it captures the expected component of illiquidity. The residual, $v_{m}$, represents the unexpected component of illiquidity and it is empirically demonstrated to have a negative impact on contemporaneous stock returns (Amihud, 2002). However, for the model to be consistent, the error term $v_{m}$ must be a white noise with mean zero and constant variance $\left(\epsilon_{v}{ }^{2}\right)$. Otherwise, it is hard to support the claim that unexpected illiquidity is temporary. Using a MSM we allow for the existence of two distinct periods of high and low illiquidity, rather than a unique state implicitly identified by the AR process through the parameter $c_{0}$.
We test for the existence of two distinct and persistent illiquidity states, indicating periods of low and high illiquidity, using MSM. This non-linear methodology also fits better the financial reality and the theoretical standpoint of liquidity spirals (Brunnermeier \& Pedersen, 2009). MSMs are used to model time-series that are believed to transition over a finite set of unobserved states, according to an unobserved random variable, $z_{t}$ which takes finite integer values. While the number of regimes is discrete and finite, the time of transition and the duration between changes in state is random and this transition is described by a Markov chain. We follow (Hamilton, 1989), whereby the matrix of transition probabilities, i.e. the probability of switching between regimes, is estimated with maximum likelihood. We assume two regimes, indicating high and low illiquidity, similar to the bull and bear markets proposed in other studies (Billio \& Pelizzon, 2000; Vendrame, Guermat, \& Tucker, 2018). We follow this approach to model market and portfolio returns as a two state Markov model. Given an unobserved state variable, $z_{t}$, it follows that:

$$
\begin{gathered}
p\left[z_{t}=1 \mid z_{t-1}=1\right]=p_{11} \\
p\left[z_{t}=2 \mid z_{t-1}=1\right]=1-p_{11} \\
p\left[z_{t}=2 \mid z_{t-1}=2\right]=p_{22} \\
{\left[z_{t}=1 \mid z_{t-1}=2\right]=1-p_{22}}
\end{gathered}
$$

In the above equations, $p_{11}$ and $p_{22}$ indicate the probabilities that the variable stays in the same states, 1 and 2 respectively, given the information available at time $t-1$, while $1-p_{11}$ and $1-p_{22}$ are the probabilities of a switch in regime.

Given these specifications and assuming that the process evolves as a first-order time stationary Markov chain, Eq. 4 can be rewritten as:

$\ln A I L L I Q_{s, m}=c_{z_{m}}^{0}+c_{z_{m-1}}^{1} \ln A I L L I Q_{s, z_{m-1}}+v_{m}$

where the subscripts of the estimated parameters indicate the state of the variable in the previous month $m, z_{t}=1,2$. Therefore, the low and high illiquidity states can be represented by the vectors:

$$
\begin{aligned}
\ln A I L L I Q_{s, m} & =\left(\begin{array}{l}
\ln A I L L I Q_{z_{1}} \\
\ln A I L L I Q_{z_{2}}
\end{array}\right), c_{z_{m}}^{0} \\
& =\left(\begin{array}{c}
c_{z_{1}, m}^{0} \\
c_{z_{2}, m}^{0}
\end{array}\right), c_{z_{m}}^{1} \\
& =\left(\begin{array}{c}
c_{z_{1}, m-1}^{1} \\
c_{z_{2}, m-1}^{1}
\end{array}\right)
\end{aligned}
$$

Since the work of (Hamilton, 1989), who models the growth rate of Gross Domestic Product (GDP) as a switching process to capture the asymmetrical behaviour of expansion and recession phases, the use of MSM has been widely applied in the literature. ${ }^{3}$

3 For a complete theoretical review of MRS models in economics and finance see Guidolin (2011). 
Within asset pricing, Billio and Pelizzon (2000) formulate a switching regime beta model for the estimation of value-at-risk portfolio returns. Acharya, Amihud, and Bharath (2013) examine different states of US-corporate bonds and Watanabe and Watanabe (2008) use an MRS model based on a detrended aggregate share turnover, directly on a time-series of liquidity betas obtained from mimicking portfolios to test liquidity risk. Recently, Vendrame et al. (2018) model US stock returns finding persistence of a bull and a bear market using MRS models. Instead, we firstly assess the existence of two regimes of market illiquidity, to further investigate time-varying risk premia, conditional on the illiquidity state.

\subsection{Regime switching conditional L-CAPM}

The effects of persistent periods of low and high illiquidity have important implications on the pricing of liquidity risk. To asses these implications, we develop a conditional L-CAPM where the liquidity betas are conditional on the state of illiquidity in the market. The unconditional model relates expected net returns to transaction costs and market returns, assuming constant conditional covariances of innovations in illiquidity and returns. It can be written as:

$E\left(r_{t}^{i}-r_{t}^{f}\right)=E\left(c_{t}^{i}\right)+\lambda_{t}^{1} \beta_{i}^{1}+\lambda_{t}^{2} \beta_{i}^{2}+\lambda_{t}^{3} \beta_{i}^{3}+\lambda_{t}^{4} \beta_{i}^{4}$

where:

$$
\begin{aligned}
& \beta_{i}^{1}=\frac{\operatorname{cov}\left(r_{t}^{i}, r_{t}^{M}-E_{t-1}\left(r_{t}^{M}\right)\right)}{\operatorname{var}\left(r_{t}^{M}-E_{t-1}\left(r_{t}^{M}\right)-\left(c_{t}^{M}-E_{t-1}\left(c_{t}^{M}\right)\right)\right)} \\
& \beta_{i}^{2}=\frac{\operatorname{cov}\left(c_{t}^{i}-E_{t-1}\left(c_{t}^{i}\right), c_{t}^{M}-E_{t-1}\left(c_{t}^{M}\right)\right.}{\operatorname{var}\left(r_{t}^{M}-E_{t-1}\left(r_{t}^{M}\right)-\left(c_{t}^{M}-E_{t-1}\left(c_{t}^{M}\right)\right)\right)} \\
& \beta_{i}^{3}=\frac{\operatorname{cov}\left(r_{t}^{i}, c_{t}^{M}-E_{t-1}\left(c_{t}^{M}\right)\right)}{\operatorname{var}\left(r_{t}^{M}-E_{t-1}\left(r_{t}^{M}\right)-\left(c_{t}^{M}-E_{t-1}\left(c_{t}^{M}\right)\right)\right)} \\
& \beta_{i}^{4}=\frac{\operatorname{cov}\left(c_{t}^{i}-E_{t-1}\left(c_{t}^{i}\right), r_{t}^{M}-E_{t-1}\left(r_{t}^{M}\right)\right.}{\operatorname{var}\left(r_{t}^{M}-E_{t-1}\left(r_{t}^{M}\right)-\left(c_{t}^{M}-E_{t-1}\left(c_{t}^{M}\right)\right)\right)}
\end{aligned}
$$

and $\lambda_{t}=E_{t}\left(r_{t}^{M}-c_{t}^{M}-r_{f}\right)$. Asset-specific and market-wide illiquidity costs are represented by $c_{t}^{i}$ and $c_{t}^{M}$ and proxied by the illiquidity measure of Amihud (2002). The first term on the right-hand side of Eq. 8 indicates the asset-specific expected illiquidity and corresponds also to the premium for holding an illiquid security, as found theoretically and empirically by (Amihud \& Mendelson, 1986). The model is decomposed into four betas where the numerator captures four different sources of systematic risk. The $\operatorname{cov}\left(r_{t}^{i}, r_{t}^{M}\right)$ is simply the systematic risk of the CAPM and the other three unconditional covariances capture different channels through which liquidity costs affect stock returns, thatis three forms of liquidity risk. The $\operatorname{cov}\left(c_{t}^{i}, c_{t}^{M}\right)$ captures liquidity commonality. The $\operatorname{cov}\left(r_{t}^{i}, c_{t}^{M}\right)$ refers to the covariation between stock returns and market liquidity and finds empirical sup- port in Pástor and Stambaugh (2003), while $\operatorname{cov}\left(c_{t}^{i}, r_{t}^{M}\right)$ captures the co-movements of stock liquidity with market returns. It is interesting to note that the betas above are not the classical slope coefficients of the CAPM, represented by the ratio $\frac{\operatorname{Cov}\left(r_{i}, r_{m}\right)}{\operatorname{Var}\left(r_{m}\right)}$. To account for the unexpected component of illiquidity, Acharya and Pedersen (2005) employ the common denominator of all betas using the variance of the difference between innovations in returns and illiquidity, obtained as residuals from an AR(2) process. Our approach starts from the widely accepted view that liquidity is persistent and that investors have one-period expectations about future liquidity (see Eq. 4). Therefore, the expected return, based on expected illiquidity can be represented as follows:

$$
E\left(r_{t+1}^{i}-r_{f} \mid \ln A I L L I Q_{t}^{E}\right)=f_{0}+f_{1} A I L L I Q_{t}^{E}
$$

This formula implies that the increasing concave relationship between illiquidity and stock returns depends on expected illiquidity $\left(\ln A I L I I Q_{t}^{E}\right)$, which is assumed to be linearly related to future illiquidity. Amihud (2002) finds that expected illiquidity is an increasing function of expected stock returns, while unexpected illiquidity has a negative effect on unexpected contemporaneous stock returns. Using monthly frequencies, he estimates an autocorrelation coefficient $\left(f_{1}\right)$ of 0.945 , while Acharya and Pedersen (2005) of 0.87. Moreover, they find that the innovations in illiquidity, corresponding to the errors of an AR(2) process, are significantly priced in their unconditional model. As a result, the error term $v_{m}$ in Eq. 4 corresponds to the innovations employed in Amihud (2002) and is similar to those described in Acharya and Pedersen (2005).

All these assumptions require linearity of the illiquidity time-series. As a result, innovations are temporary and average level of illiquidity is assumed constant over the entire time-series. We develop a conditional version of the L-CAPM, where asset-specific liquidity betas are conditional on the state of liquidity in the market. This setting relaxes the assumption of constant covariances assumed in the model of Acharya and Pedersen (2005) and thereby extends the analysis. If illiquidity shocks are persistent, they generate a persistent illiquidity regime. Therefore, investors' one period expectation about future illiquidity is not a function of average illiquidity, as in prior work, but instead of the expected future illiquidity regime. Combining Eqs. (4) and (13), we obtain:

$E\left(r_{t+1}^{i}-r_{f} \mid \ln A I L L I Q_{z_{t}}^{E}\right)=f_{0, z_{t}}+f_{1, z_{t}} A I L L I Q_{z_{t}}^{E}$

where the parameters of the model are vectors that capture the different states of the Markov chain, similar to Eq. (7). This model can also be represented in a similar fashion to Kim, Morley, and Nelson (2004), as:

$$
\begin{aligned}
& E\left(r_{t+1}^{i}-r_{f} \mid \ln A I L L I Q_{t}\right)=\mu_{0} \\
& \quad+\mu_{1} \operatorname{Pr}\left[z_{t+1}=1 \mid \ln A I L L I Q_{t}\right]
\end{aligned}
$$

where $\mu_{0}$ is the expected net return in a perfectly an- 
ticipated low illiquidity regime and $\mu_{1}$ is the marginal effect on the expected net return of a perfectly anticipated high illiquidity regime. In addition, in line with previous research that identifies two regimes for market returns, indicating bull and bear cycles (Vendrame et al., 2018), we estimate conditional covariances of illiquidity and returns using a two-regime MSM for the market return series. The estimation of market and illiquidity betas described by Eqs. (8)-(12) is adapted by taking into consideration the regimes of market returns and illiquidity. We thus formulate our variables of interest as follows: $\boldsymbol{E}\left(c_{i}\right)$ : we calculate expected illiquidity cost using an MSM with two states for each security (portfolio) in the sample. We obtain two intercepts, which indicate low and high illiquidity levels for each portfolio. We then estimate a probability weighted expected illiquidity using probabilities extracted from the transition matrix. That is:

$$
\begin{aligned}
E\left(c_{p}\right) & =\mu_{p, 1} \operatorname{Pr}\left(z_{t}\right. \\
& \left.=1 \mid c_{p, t}\right)+\left(\mu_{p, 2}-\mu_{p, 1}\right) \operatorname{Pr}\left(z_{t}\right. \\
& \left.=2 \mid c_{p, t}\right)
\end{aligned}
$$

where $\mu_{p, 1}$ and $\mu_{p, 2}$ are the intercepts for low and high illiquidity of each portfolio.

The common denominator of all betas in the unconditional version, $\operatorname{var}\left[r_{t}^{M}-E_{t-1}\left(r_{t}^{M}\right)-\left(c_{t}^{M}-E_{t-1}\left(c_{t}^{M}\right)\right)\right]$, which captures the market return net of transaction costs is found using regime-dependent residuals. In the unconditional version, $r_{t}^{M}-E_{t-1}\left(r_{t}^{M}\right)$ and $c_{t}^{M}-E_{t-1}\left(c_{t}^{M}\right)$ are obtained from the residuals of an $\mathrm{AR}(2)$ process on market returns and illiquidity. Here, we extract the regime specific residuals from the two time series and we weight the overall unexpected component using the extracted filtered probabilities for each regime. We then find the variance of the net market return obtained using probability-weighted residuals of gross market return and illiquidity. Algebraically:

$\left(r_{t}^{M}-E_{t-1}\left(r_{t}^{M}\right) \mid z_{t}\right)=r_{t}^{M}-E_{t-1}\left(r_{t}^{M}\right) \operatorname{Pr}\left(z_{t}=1\right)$

$+\left[\left(r_{t}^{M}-E_{t-1}\left(r_{t}^{M}\right) \mid z_{t}=1\right)-\left(r_{t}^{M}-E_{t-1}\left(r_{t}^{M}\right) \mid z_{t}=2\right)\right] \operatorname{Pr}\left(z_{t}=\right.$

$\left(c_{t}^{M}-E_{t-1}\left(c_{t}^{M}\right) \mid z_{t}\right)=c_{t}^{M}-E_{t-1}\left(c_{t}^{M}\right) \operatorname{Pr}\left(z_{t}=1\right)$

$+\left[\left(c_{t}^{M}-E_{t-1}\left(c_{t}^{M}\right) \mid z_{t}=1\right)-\left(c_{t}^{M}-E_{t-1}\left(c_{t}^{M}\right) \mid z_{t}=2\right)\right] \operatorname{Pr}\left(z_{t}=\right.$

$\operatorname{var}\left[r_{t}^{M}-E_{t-1}\left(r_{t}^{M}\right)-\left(c_{t}^{M}-E_{t-1}\left(c_{t}^{M}\right)\right)\right]$

$=\operatorname{var}\left[r_{t}^{M}-E_{t-1}\left(r_{t}^{M}\right)-\left(c_{t}^{M}-E_{t-1}\left(c_{t}^{M}\right)\right) \mid z_{t}\right]$

$\boldsymbol{\beta}_{1}$. : the denominator explained in Eqs. (16)-(18) is common to all the conditional betas. Therefore, the estimation changes for each numerator. The conditional covariance between security returns and unexpected market returns, $\beta_{1}$, is obtained from the regime-dependent variance-covariance matrix of residuals from the simultaneous Markov switching model from the following equations:

$\left\{\begin{array}{l}r_{t}^{M}=\mu\left(z_{t}\right)+\omega_{m}\left(z_{t}\right) \zeta_{t} \\ r_{t}^{i}=\alpha+\gamma_{i} r_{t}^{M}+\omega_{i}\left(z_{t}\right) \epsilon_{t}\end{array}\right.$

where the first equation in the model is a simple MSM with two states for market returns, with regime-dependent intercept and variance. The second equation is an MSM with unconditional intercept and regime-dependent slope $\left(\gamma_{i}\right)$. We extract the variance covariance matrix of the residuals, conditional on each state of the market and we take the covariance as the numerator to find $\beta_{1} \cdot{ }^{4}$

$\boldsymbol{\beta}_{2}$ : regime-dependent commonality beta is computed in a similar fashion to $\beta_{1}$. The numerator is found using the regime-dependent conditional covariances extracted from the simultaneous equation model:

$\left\{\begin{array}{c}c_{t}^{M}=\mu\left(z_{t}\right)+\omega_{\mathrm{m}}\left(z_{t}\right) \zeta_{t} \\ r_{t}^{i}=\alpha+\gamma_{i} c_{t}^{M}+\omega_{i}\left(z_{t}\right) \epsilon_{t}\end{array}\right.$

Lastly, we find the covariances for $\beta_{3}$ and $\beta_{4}$ using the following two simultaneous equation models:

$\left\{\begin{array}{l}r_{t}^{M}=\mu\left(z_{t}\right)+\omega_{m}\left(z_{t}\right) \zeta_{t} \\ c_{t}^{i}=\alpha+\gamma_{i} r_{t}^{M}+\omega_{i}\left(z_{t}\right) \epsilon_{t}\end{array}\right.$

$\left\{c_{t}^{M}=\mu\left(z_{t}\right)+\omega_{m}\left(z_{t}\right) \zeta_{t}\right.$

$\left\{r_{t}^{i}=\alpha+\delta_{i} c_{t}^{M}+\omega_{i}\left(z_{t}\right) \epsilon_{t}\right.$

For each of the above covariances, $\mu\left(z_{t}\right)$ is the regime-dependent return (illiquidity) level, $\omega_{m}$ and $\omega_{i}$ are the conditional variances for the market and each security and $\alpha, \gamma$ and $\delta$ are parameters to be estimated. These covariances are obtained in a similar manner to the linear procedure of Acharya and Pedersen (2005), but here we allow for persistent periods of high and low illiquidity, and bull and bear markets. From these specifications, we can rewrite Eq. 8, considering the new covariances as follows:

$$
\begin{aligned}
E\left(r_{t}^{i}-r_{t}^{f}\right) & =\lambda_{t}^{0}\left[E\left(c_{t}^{i} \mid z_{t+1}\right) \operatorname{Pr}\left(z_{t+1}=1 \mid c_{t}^{M}\right)+\Delta E\left(c_{t}^{i} \mid z_{t+1}\right.\right. \\
+ & \lambda_{t}^{1}\left[\left(\beta_{i, I}^{1} \mid z_{t+1}\right) \operatorname{Pr}\left(z_{t+1}=1 \mid r_{t}^{M}\right)+\Delta \beta_{i}^{1} \operatorname{Pr}\left(z_{t+1}\right.\right. \\
+ & \lambda_{t}^{2}\left[\left(\beta_{i, I}^{2} \mid z_{t+1}\right) \operatorname{Pr}\left(z_{t+1}=1 \mid c_{t}^{M}\right)+\Delta \beta_{i}^{2} \operatorname{Pr}\left(z_{t+1}\right.\right. \\
+ & \lambda_{t}^{3}\left[\left(\beta_{i, I}^{3} \mid z_{t+1}\right) \operatorname{Pr}\left(z_{t+1}=1 \mid r_{t}^{M}\right)+\Delta \beta_{i}^{3} \operatorname{Pr}\left(z_{t+1}\right.\right. \\
+ & \lambda_{t}^{4}\left[\left(\beta_{i, I}^{4} \mid z_{t+1}\right) \operatorname{Pr}\left(z_{t+1}=1 \mid c_{t}^{M}\right)+\Delta \beta_{i}^{4} \operatorname{Pr}\left(z_{t+1}=\right.\right.
\end{aligned}
$$

where $\Delta$ represents the difference between the conditional beta for regime 2 and the conditional beta for regime 1 for each $k$ beta, with $k=1, \quad 2, \quad 3, \quad 4, \quad$ assum-

4 This approach is similar to Billio and Pelizzon (2000). 
ing regime 2 higher than regime 1, i.e.:

$\Delta=\left(\beta_{i, 2}^{k} \mid z_{t+1}=2\right)-\left(\beta_{i, 1}^{k} \mid z_{t+1}=1\right)$

The probabilities are the forecast transition probabilities of a switch in regime, $\operatorname{Pr}\left(z_{t+1}=1 \mid c_{t}^{M}\right)$ and $\operatorname{Pr}\left(z_{t+1}=2 \mid c_{t}^{M}\right)$. We use as risk-free rate $\left(r_{t}^{f}\right)$, the 3-month money market interest rate for Germany for all country. Although this rate is specific to one country, it can undoubtedly be considered the closest proxy of a risk-free security within the Euro area. We exploit a further benefit arising from our estimation, by analysing the premium corresponding to each regime. In other words, we reformulate Eq. (23), splitting betas into high and low regimes:

$$
\begin{array}{r}
E\left(r_{t}^{i}-r_{t}^{f}\right)=\lambda_{t, L}^{0} E\left(c_{t}^{i} \mid z_{t+1}\right) \operatorname{Pr}\left(z_{t+1}=1 \mid c_{t}^{M}\right)+\lambda_{t, H}^{0} E\left(c_{t}^{i} \mid z_{t-}\right. \\
\lambda_{t, L}^{1}\left(\beta_{i, I}^{1} \mid z_{t+1}\right) \operatorname{Pr}\left(z_{t+1}=1 \mid r_{t}^{M}\right)+\lambda_{t, H}^{1}\left(\beta_{i, I}^{1} \mid z_{t+1}\right) \operatorname{Pr} \\
\lambda_{t, L}^{2}\left(\beta_{i, I}^{2} \mid z_{t+1}\right) \operatorname{Pr}\left(z_{t+1}=1 \mid c_{t}^{M}\right)+\lambda_{t, H}^{2}\left(\beta_{i, I}^{2} \mid z_{t+1}\right) \operatorname{Pr} \\
\lambda_{t, L}^{3}\left(\beta_{i, I}^{3} \mid z_{t+1}\right) \operatorname{Pr}\left(z_{t+1}=1 \mid r_{t}^{M}\right)+\lambda_{t, H}^{3}\left(\beta_{i, I}^{3} \mid z_{t+1}\right) \operatorname{Pr} \\
\lambda_{t, L}^{4}\left(\beta_{i, I}^{4} \mid z_{t+1}\right) \operatorname{Pr}\left(z_{t+1}=1 \mid c_{t}^{M}\right)+\lambda_{t, H}^{4}\left(\beta_{i, I}^{4} \mid z_{t+1}\right) \operatorname{Pr}(z
\end{array}
$$

This second set of empirical estimation is more informative in the sense that it provides insights with respect to the risk premium conditional on the covariance between securities and the market for each regime. We thus estimate the $\lambda$ parameterfor each regime and for each $\beta$.

\subsubsection{Construction of portfolios}

We test our conditional L-CAPM model for each market in the sample using monthly illiquidity and returns. In line with Acharya and Pedersen (2005) and Watanabe and Watanabe (2008), we form 25 portfolios for each year, sorting stocks based on their level of illiquidity in the previous year. We compute the annual level of illiquidity for each eligible stock as the simple average of monthly observations. Stocks are then sorted into 25 portfolios, based on their previous year illiquidity. The benefit of using portfolios, rather than individual stocks has been widely acknowledged since the work of Fama and MacBeth (1973). We compute the relevant monthly illiquidity and return as the equally weighted average of individual stocks for each illiquidity ranked portfolio, in line with past research (Amihud, 2002; Chordia et al., 2000).

A number of countries are analysed in our paper. For our dataset, the number of available securities changes from year to year. While large stock markets, such as Germany and France are included, we also investigate more peripheral economies such as Italy and Spain, which exhibit more data constraints. To achieve reliable estimates we only include years in which there are at least 5 securities for each portfolio and a total of 125 stocks exist in the market. This filter results in the exclusion of Austria, Ireland, the Netherlands and Portugal from the empirical estimation of the conditional L-CAPM.

\subsubsection{Empirical estimation}

We run cross-sectional regressions of the 25 illiquidity sorted portfolios for each month, similar to Acharya and Pedersen (2005) and Fama and MacBeth (1973). We provide different specifications and use alternative estimation techniques. First, we estimate Eq. (23) using a standard OLS procedure. In addition, we provide robustness tests using GMM and pooled OLS regressions within a panel framework, which avoids taking the average of the estimated parameters. We repeat these estimations for Eq. (24) as well to get the contribution of low and high return and illiquidity regimes to the risk premium of each portfolio.

\section{Data and descriptive statistics}

Our initial sample comprises of daily adjusted closing prices and volumes for all the stocks listed in eleven Eurozone countries, namely Austria, Belgium, Finland, France, Germany, Greece, Ireland, Italy, Netherland, Portugal and Spain. All market data have been collected from Thomson Reuters Datastream (TRD) for the period from 01/01/1990 to $31 / 12 / 2018$. The length of the time span allows us to highlight the evolution of illiquidity within each country, including remarkable events, such as the GFC or the euro crisis. The euro crisis has proven to be one of the most challenging events to the stability of the Euro area (e.g. see Ferreira, Dionísio, Guedes, \& Zebende, 2018). All individual stock returns are obtained as the log difference of daily subsequent prices, $r_{i, t}=\ln \left(p_{i, t}\right)-\ln \left(p_{i, t-1}\right)$. Previous research observes that equity data from TRD must be handled with care (Andrikopoulos et al., 2014). To reduce the risk of data errors, we apply a series of filters, following Ince and Porter (2006) and Lee (2011). Specifically, only domestic stocks recorded as equity in DataStream and listed in the main stock exchange for which data are available are included. Moreover, data are cleaned from possible biases using the following filters: i) zero daily returns are coded as missing; ii) daily returns are coded as missing if they are $>200 \%$ and if $\left(1+r_{i, d}\right) *\left(1+r_{i, d-1}\right)-1 \leq 50 \%$; iii) daily returns are coded as missing if their drop in value is $>97 \%$; iv) Stocks with daily volume greater than the number of share outstanding are deleted; v) daily volumes are coded as missing if their value is smaller than $100 €$; vi) market days in which $>90 \%$ stocks have zero returns are excluded. Furthermore, in constructing portfolios, we only keep years in which at least 5 stocks for each portfolio have available data. This procedure results in the exclusion of 4 countries, Austria, Ireland, Netherlands and Portugal from our analysis. ${ }^{5}$

Table 1 shows the summary statistics for the final sample of seven Eurozone countries. Panel A shows

5 Despite these countries being excluded from the Markov switching L-CAPM analysis, we still report descriptive statistics and time-varying Markov estimation for all 11 countries. These findings are available as online appendix. 
Table 1

Stochastic properties of illiquidity series.

\begin{tabular}{|c|c|c|c|c|c|c|c|c|}
\hline & Observations & Mean & SD & Kurtosis & Skewness & Min & Max & JB-test $p$-value \\
\hline \multicolumn{9}{|c|}{ Panel A: Market returns } \\
\hline Belgium & 276 & 0.484 & $98 \%$ & 4.822 & 0.865 & -2.238 & 4.714 & 0.000 \\
\hline Finland & 228 & -0.058 & $41 \%$ & 4.218 & -0.156 & -1.655 & 1.287 & 0.000 \\
\hline France & 324 & -0.192 & $51 \%$ & 5.402 & -0.539 & -2.889 & 1.552 & 0.000 \\
\hline Germany & 228 & 0.644 & $87 \%$ & 3.108 & -0.087 & -1.953 & 3.814 & 0.792 \\
\hline Greece & 324 & -0.238 & $75 \%$ & 3.428 & -0.105 & -2.292 & 2.521 & 0.194 \\
\hline Italy & 300 & -0.053 & $39 \%$ & 4.767 & 0.332 & -1.271 & 1.680 & 0.000 \\
\hline Spain & 312 & -0.015 & $39 \%$ & 3.944 & -0.124 & -1.182 & 1.501 & 0.001 \\
\hline \multicolumn{9}{|c|}{ Panel B: Market Illiquidity } \\
\hline Belgium & 276 & 2.658 & $57 \%$ & 2.515 & -0.650 & 1.260 & 3.805 & 0.000 \\
\hline Finland & 228 & 0.862 & $62 \%$ & 2.237 & 0.170 & -0.427 & 2.279 & 0.042 \\
\hline France & 324 & 2.465 & $21 \%$ & 2.799 & 0.399 & 1.952 & 3.038 & 0.010 \\
\hline Germany & 228 & 2.186 & $29 \%$ & 2.517 & 0.277 & 1.567 & 3.049 & 0.083 \\
\hline Greece & 324 & 1.446 & $96 \%$ & 1.890 & 0.048 & -0.454 & 3.308 & 0.000 \\
\hline Italy & 300 & -0.357 & $44 \%$ & 7.716 & -1.262 & -2.687 & 0.473 & 0.000 \\
\hline Spain & 312 & -0.001 & $50 \%$ & 2.912 & 0.421 & -1.056 & 1.610 & 0.009 \\
\hline
\end{tabular}

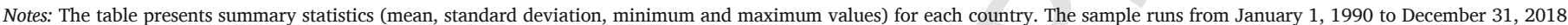

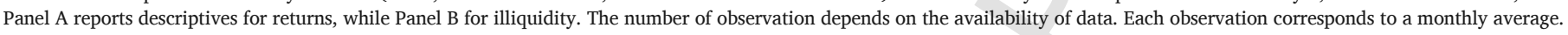

the characteristics of market returns, while Panel B shows market illiquidity measures. Both measures are obtained as the equally-weighted average of individual stocks' measures. The number of observations (number of months) changes according to the availability of data, that is the number of years with at least 5 stocks in each of the 25 portfolios. In Panel B, it can be seen that Belgium is the most illiquid market, while Italy is the least illiquid. Moreover, illiquidity time series are positively skewed for most markets and they show an excess kurtosis substantially $>0$, indicating a deviation from the normality assumption. The last column of Table 1 reports the $p$-value of the Jarque-Bera (JB) test that shows that the null hypothesis of normal distribution cannot be rejected at the 5\% significance level only for Germany. The features of skewness and kurtosis are consistent with the existing findings around the characteristics of illiquidity. In particular, regarding kurtosis, it is extensively reported in the literature that sudden and pervasive drops characterise financial markets, as is the case for the October 1987 crash (Roll, 1988). Similar conclusions can be reached with respect to returns, where the assumption of normality is rejected for all countries except Germany and Greece.

While Table 1 provides preliminary insights into the characteristics of the returns and illiquidity series, we are more interested in testing whether the time series are stationary or not. One of the key justifications for using a non-linear method such as MSM arises from evidence on non-stationarity or, more appropriately, regime stationarity. For instance, (Chordia et al., 2000) note that illiquidity measures are subject to econometric problems. We test the null hypothesis of a unit-root using the augmented Dickey Fuller (Dickey \& Fuller, 1981) test and the null of a stationary distribution using the KPSS (Kwiatkowski, Phillips, Schmidt, \& Shin, 1992) test. We perform these tests on the illiquidity time-series, on which our paper places key emphasis. We report the results of the ADF-test without drift and trend. Other specifications of the ADF provide generally consistent results (these are available on request). The maximum number of lags is 10 , which is selected so as to minimise the BIC criterion. The KPSS test evaluates level-stationarity. In addition to these well-established tests, we carry out unit root tests allowing for the existence of structural breaks. As is well known in this literature, structural breaks can invalidate unit root test results (e.g., see Andrews, 1993; Garcia \& Perron, 1996; Lee \& Strazicich, 2003).

In results not reported here for reasons of brevity, ${ }^{6}$ we find that all our series are characterised by structural changes using two different procedures, which include CUSUM (cumulative sum) tests, as well as the Chow test (Andrews, 1993). To test for unit roots in the presence of structural changes, we employ the Zivot-Andrews unit-root test (Zivot \& Andrews, 1992), which allows for one break in the time-series and the Lee-Strazicich test (Lee \& Strazicich, 2003), which allows for two breaks. In both cases, the breaks are endogenously determined. We report the Zivot-Andrews test including a drift and a time-trend, although we also estimate a model without trend and without drift and trend. Our results are presented in Table 2 . The null hypothesis of a unit-root can be rejected only for Italy and Spain at $5 \%$ significance level. We find confirmatory evidence for this using the KPSS test. The test-statistics for the null hypothesis of a stationary distribution indicate a rejection of the null at 5\% level for all markets except Germany and Italy. Given the documented evidence indicating structural changes, we provide two further tests for unit roots which allow for the presence of structural breaks. The penultimate row shows test-statistics from the Zivot-Andrews (ZA) test, which allows for one endogenous break in the data. The null hypothesis of a unit-root using the ZA test can be rejected only for Spain at all significance levels and for Finland, only at 5\%, but not at

\footnotetext{
6 These tests are available in an online appendix to this paper.
} 
Table 2

Unit root test on lnilliq.

\begin{tabular}{|c|c|c|c|c|c|c|c|}
\hline & Belgium & Finland & France & Germany & Greece & Italy & Spain \\
\hline \multicolumn{8}{|l|}{$H_{0}$ : Unit-root } \\
\hline $\mathrm{ADF}$ & -0.515 & -1.885 & -0.536 & 0.133 & -0.878 & -3.319 & -4.876 \\
\hline \multicolumn{8}{|l|}{$H_{0}$ : Statioanrity } \\
\hline \multicolumn{8}{|l|}{$H_{0}:$ Unit-root } \\
\hline Zivot-Andrews & -4.386 & -5.334 & -4.386 & -3.176 & -3.347 & -4.958 & -5.752 \\
\hline Lee-Strazicich & -5.861 & -6.608 & -6.291 & -3.810 & -5.579 & -5.224 & -7.374 \\
\hline
\end{tabular}

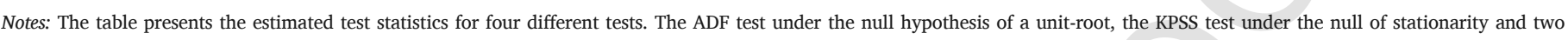

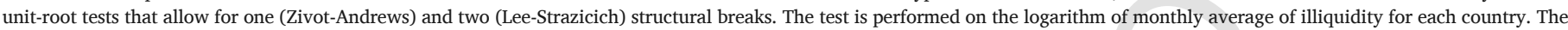

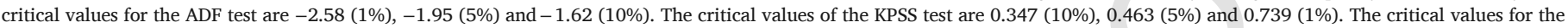
Zivot-Andrews test are $-5.570(1 \%),-5.080(5 \%)$ and $-4.820(10 \%)$.

$1 \%$ levels. The Lee-Strazicich tests suggest the presence of unit roots only for Germany, while the null hypothesis can be rejected for all other markets at 5\% level. Overall, our results indicate strong evidence of a unit-root, even after controlling for structural changes in the time-series, thus providing empirical support for the choice of non-linear models in lieu of AR(p) processes. This is especially true since unit root tests are low power tests and evidence suggesting presence of unit roots has to be carefully taken into account.

These results notwithstanding it is important to note the following. While unit root test results (including allowing for structural breaks) is an important consideration, our overall approach based on use of Markov Switching Models (MSM) arises from an important limitation of $A R$ based models including problems related to non-stationarity of time-series which we wish to avoid by our implementation of MSM models. For our analysis and implementation of MSM models, what is important is regime stationarity and not the presence of unit roots per se or otherwise. Regime-stationarity is not important for the ensuring stability of the parameters, since different regimes are not identified using BLUE type estimators typically computed using OLS method. Instead, our regimes are obtained by minimising the log-likelihood function. OLS is clearly invalid in the presence of unit roots but for our estimation of MSM models, the key issue is regime stationarity which crucially does not refer to or relate to model parameters but to the matrix of transition probabilities which are derived from an ergodic time-invariant Markov chain using maximum likelihood methods.

\section{Empirical results}

In this section, we investigate the time-varying nature of illiquidity and its effects with respect to pricing of liquidity risk for our set of Eurozone countries. In Section 1, we test our initial hypotheses on the characteristics of illiquidity time series. The standard AR(1) process is compared with an MRS model with two states, indicating periods of high and low illiquidity, with regime dependent intercepts and variances.

\subsection{Autoregressive illiquidity: one vs multiple states}

Time-varying illiquidity is first analysed using the AR(1) model shown in Eq. (4) for each monthly market illiquidity average of Belgium, Finland, France, Germany, Greece, Italy and Spain. Table 3 reports our empirical results. All the coefficients are positive and significant, indicating common patterns in terms of illiquidity persistence within the Eurozone. Furthermore, even though the magnitude of the AR coefficients changes from country to country, it is generally consistent with previous evidence for the US market. ${ }^{7}$ Core economies such as Germany and France show high persistence in general, with a coefficient of 0.807 and 0.687 , respectively. In contrast, Spain reports the lowest persistence (0.48). The intercepts substantially support our descriptive statistics reported in Table 1, which identify Italy as the least illiquid country and Belgium and France as the most illiquid.

We conduct a series of diagnostic tests to investigate the reliability of these findings from an econometric perspective. In unreported plots, we observe that residuals do not seem to be white noise and they appear to suffer from autocorrelation. Therefore, we provide further specification tests for the AR(1) processes in Table 4, which shows the results of the Ljung-Box (LB) test for the null of independence of the residuals and the Breusch-Pagan test for the null of homoskedasticity. For each test, we report the $\chi^{2}$ test statistics and the associated $p$-value. Results show that autocorrelation within residuals is a serious issue in the AR(1) model of illiquidity time-series, where the null hypothesis is strongly rejected for all countries. In contrast, the null of homoskedasticity is rejected only for four countries in our sample at $5 \%$ significance level. These diagnostics, together with the presence of unit-roots, even after accounting for structural breaks, suggest that the parameters obtained using the linear model may not be reliable and a non-

7 (Amihud, 2002) finds a highly significant autoregressive coefficient of 0.768 and an $R^{2}$ of 0.53 (annual frequency), while (Acharya \& Pedersen, 2005) find a coefficient of 0.87 and an $R^{2}$ for a $\mathrm{AR}(2)$ specification of 0.78 . 
Table 3

Illiquidity persistence using $\operatorname{AR}(1)$ processes.

\begin{tabular}{|c|c|c|c|c|c|c|c|}
\hline $\operatorname{AR}(1)$ & Belgium & Finland & France & Germany & Greece & Italy & Spain \\
\hline Intercept & $\begin{array}{l}0.494^{* * *} \\
(-0.095)\end{array}$ & $\begin{array}{l}0.209 * * * \\
(-0.047)\end{array}$ & $\begin{array}{l}0.772^{* * *} \\
(-0.1)\end{array}$ & $\begin{array}{l}0.424^{* * *} \\
(-0.086)\end{array}$ & $\begin{array}{l}0.041^{*} \\
(-0.023)\end{array}$ & $\begin{array}{l}-0.089^{* * *} \\
(-0.021)\end{array}$ & $\begin{array}{l}-0.003 \\
(-0.025)\end{array}$ \\
\hline Coeff. $\left(c_{1}\right)$ & $\begin{array}{l}0.814^{* * *} \\
(-0.035)\end{array}$ & $\begin{array}{l}0.752^{* * *} \\
(-0.044)\end{array}$ & $\begin{array}{l}0.687^{* * * *} \\
(-0.04)\end{array}$ & $\begin{array}{l}0.807^{* * * *} \\
(-0.039)\end{array}$ & $\begin{array}{l}0.971 * * * \\
(-0.013)\end{array}$ & $\begin{array}{l}0.728^{* * *} \\
(-0.037)\end{array}$ & $\begin{array}{l}0.48^{* * *} \\
(-0.05)\end{array}$ \\
\hline$R^{2}$ & 0.663 & 0.561 & 0.473 & 0.654 & 0.943 & 0.572 & 0.231 \\
\hline AIC & 179.01 & 249.01 & -282.05 & -151.78 & -29.09 & 84.99 & 379.79 \\
\hline Obs. & 275 & 227 & 323 & 227 & 318 & 299 & 311 \\
\hline
\end{tabular}

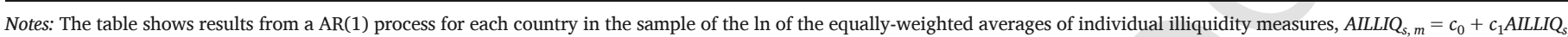
${ }_{m-1}+v_{m}$, where $c_{0}$ and $c_{1}$ represent the coefficients and $v_{m}$ is the residual. Standard errors are reported in parentheses.

Table 4

Diagnostic tests.

\begin{tabular}{|c|c|c|c|c|c|c|c|}
\hline & Belgium & Finland & France & Germany & Greece & Italy & Spain \\
\hline Ljung-Box & $\begin{array}{l}77.239 \\
(0.000)\end{array}$ & $\begin{array}{l}133.620 \\
(0.000)\end{array}$ & $\begin{array}{l}63.524 \\
(0.000)\end{array}$ & $\begin{array}{l}49.112 \\
(0.000)\end{array}$ & $\begin{array}{l}32.046 \\
(0.006)\end{array}$ & $\begin{array}{l}33.198 \\
(0.004)\end{array}$ & $\begin{array}{l}66.689 \\
(0.000)\end{array}$ \\
\hline Breusch-Pagan & $\begin{array}{l}5.289 \\
(0.021)\end{array}$ & $\begin{array}{l}8.139 \\
(0.004)\end{array}$ & $\begin{array}{l}0.332 \\
(0.565)\end{array}$ & $\begin{array}{l}0.146 \\
(0.703)\end{array}$ & $\begin{array}{l}10.453 \\
(0.001)\end{array}$ & $\begin{array}{l}7.802 \\
(0.005)\end{array}$ & $\begin{array}{l}1.216 \\
(0.270)\end{array}$ \\
\hline
\end{tabular}

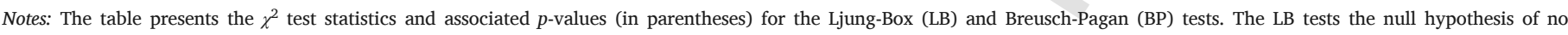
autocorrelation of the residuals from model 4 , while the BP tests the null of homoskedasticity.

linear approach is likely to be more appropriate. In particular, OLS regressions disregarding unit roots can lead to the well-known problem of spurious or biased results and inferences.

We estimate an MRS model with two states where each state represents regime-stationary average illiquidity levels. The degrees of persistence of each state is identified by the matrix of transition probabilities, which estimates the likelihood of a switch in regime between one period and the next. Table 5 shows our estimated results. We report the intercept, with respective standard errors in parentheses for each country. It can be seen that all coefficients are highly significant, indicating that shocks lead to a new state of illiquidity and that each state is persistent. The matrix of transition probabilities reports persistence of each state from one period to the following, which is found to be well above $90 \%$ probability for all countries.
In untabulated results, we observe that regime-specific residuals tend to be normally distributed and the observed autocorrelation decays considerably. Fig. 1 depicts the estimated regimes on the illiquidity time-series for each country, together with the smoothed transition probabilities. Regime 1 is represented by the grey area, while the white area refers to Regime 2 . The behaviour of illiquidity time series varies considerably between markets, in terms of regime switches. While Italy and Spain report more frequent switches, other countries in the sample indicate longer lasting regimes. We observe a gradual decrease in illiquidity following the GFC, with local peaks corresponding to the Eurodebt crisis. In fact, the Irish banking sector and the Greek sovereign debt crises, driven by liquidity shortages, seriously challenged the Eurozone's stability, forcing policy makers to suddenly take counteractions to stem possible propagation to other economies with fundamental structural

Table 5

MRS model: two states.

\begin{tabular}{|c|c|c|c|c|c|c|c|}
\hline & Belgium & Finland & France & Germany & Greece & Italy & Spain \\
\hline \multicolumn{8}{|l|}{ State 1} \\
\hline Intercept & $\begin{array}{l}1.9797^{* * *} \\
(0.0426)\end{array}$ & $\begin{array}{l}1.4972^{* * *} \\
(0.0487)\end{array}$ & $\begin{array}{l}2.3759 * * * \\
(0.0113)\end{array}$ & $\begin{array}{l}2.4941^{* * *} \\
(0.0274)\end{array}$ & $\begin{array}{l}2.2632^{* * *} \\
(0.0442)\end{array}$ & $\begin{array}{l}-0.1269^{* * *} \\
(0.0324)\end{array}$ & $\begin{array}{l}-0.3887^{* * *} \\
(0.0366)\end{array}$ \\
\hline \multicolumn{8}{|l|}{ State 2} \\
\hline Intercept & $\begin{array}{l}2.9905^{* * *} \\
(0.022)\end{array}$ & $\begin{array}{l}0.4933^{* * *} \\
(0.0477)\end{array}$ & $\begin{array}{l}2.7284 * * * \\
(0.0241)\end{array}$ & $\begin{array}{l}2.0199^{* * *} \\
(0.0187)\end{array}$ & $\begin{array}{l}0.6164 * * * \\
(0.0399)\end{array}$ & $\begin{array}{l}-0.6913^{* * *} \\
(0.058)\end{array}$ & $\begin{array}{l}0.3118^{* * *} \\
(0.0419)\end{array}$ \\
\hline p11 & $98.70 \%$ & $96.12 \%$ & $98.61 \%$ & $96.00 \%$ & $99.37 \%$ & $95.80 \%$ & $91.21 \%$ \\
\hline $\mathrm{p} 22$ & $99.37 \%$ & $97.08 \%$ & $95.86 \%$ & $98.49 \%$ & $99.37 \%$ & $94.40 \%$ & $93.37 \%$ \\
\hline AIC & 167.20 & 271.06 & -263.11 & -88.88 & 484.47 & 219.72 & 345.27 \\
\hline
\end{tabular}

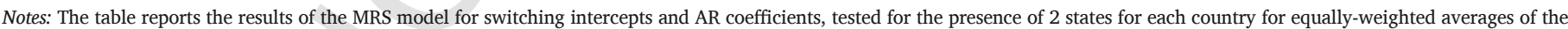

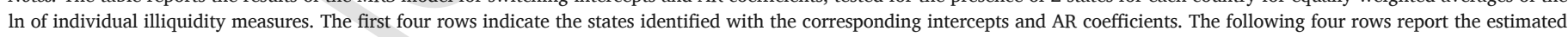

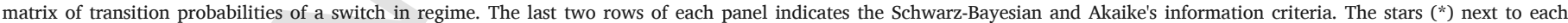
estimated intercepts and coefficients indicate the significance level: $10 \%\left({ }^{*}\right), 5 \%\left({ }^{* *}\right)$ and $1 \%(* * *)$. 


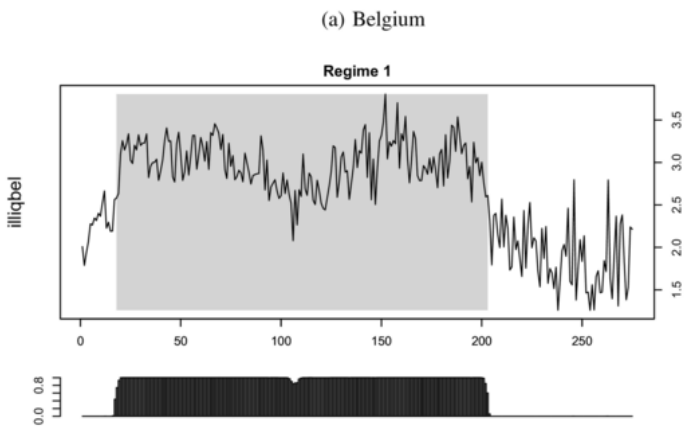

(c) France
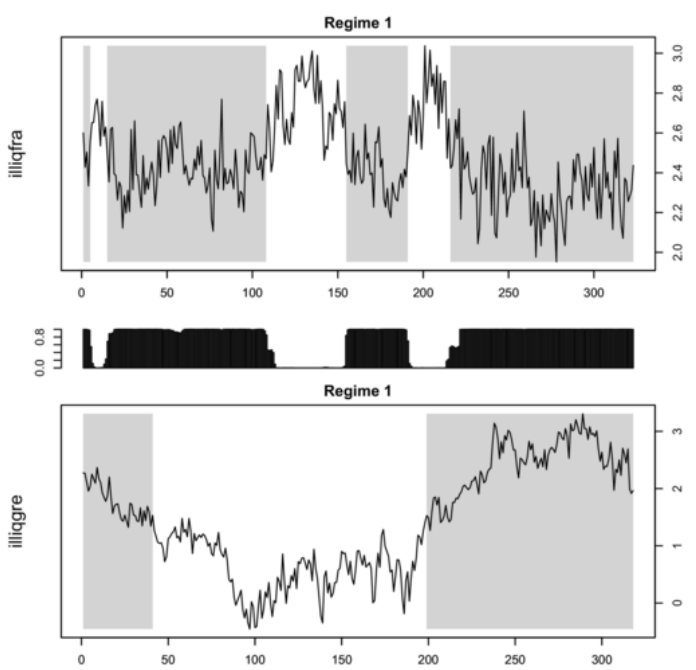

$\stackrel{\infty}{\circ}: \exists$

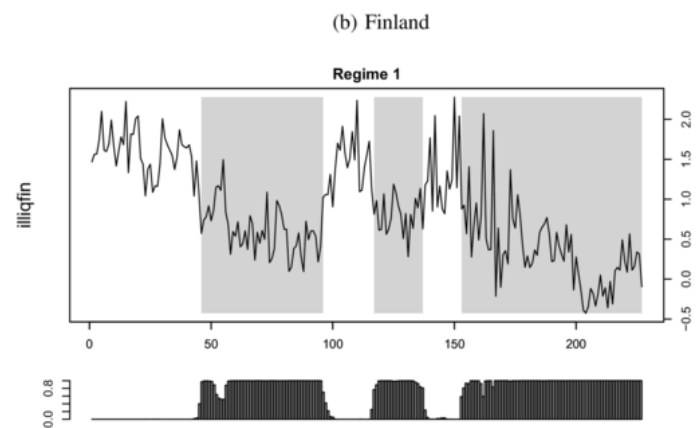

(d) Germany
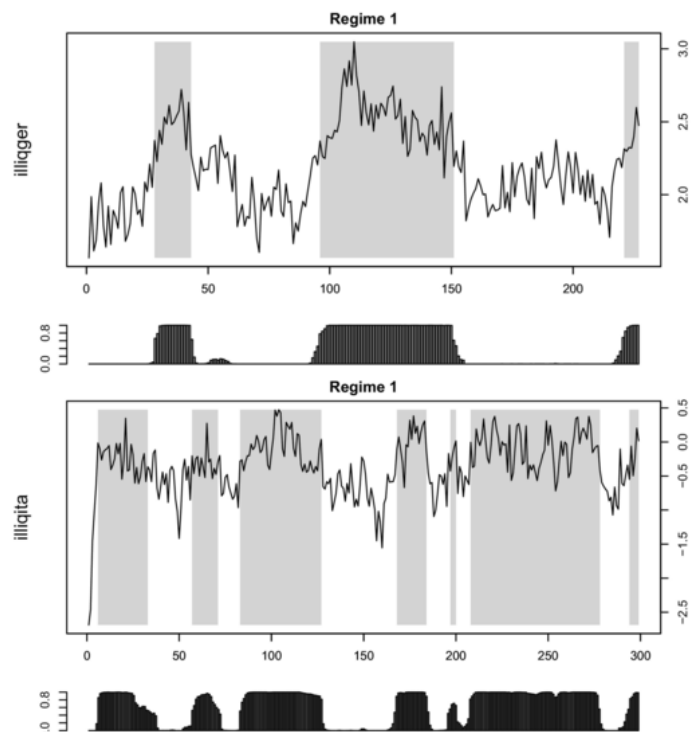

(f) Italy

(e) Greece

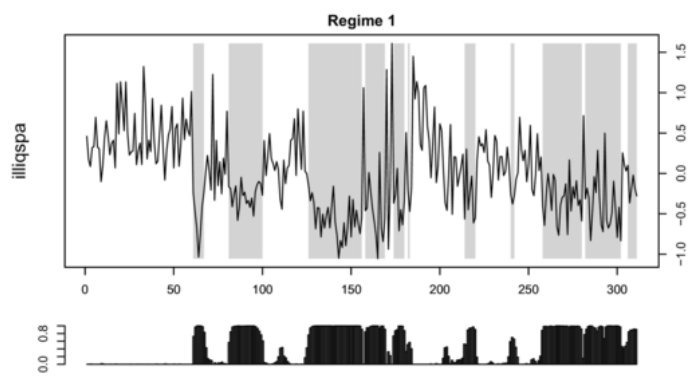

(g) Spain

Fig. 1. Regimes and transition probabilities.

weaknesses. For example, the European Central Bank(ECB) began buying assets from commercial banks in March 2015 as part of its non-standard monetary policy measures to help economic growth of Eurozone nations. One of the countries most severely hit by the Eurodebt crisis is Greece, which reports growing levels of illiquidity following the GFC. This pattern coincides with the outbreak of the Greek debt crisis, which has been widely investigated in the literature and confirmed here (see Ferreira, 2018; Ferreira \& Kristoufek, 2017). Furthermore, for each market, we can clearly observe non-stationary behaviour within the two regimes identified by our MRS estimation. Our results are in line with (Watanabe \& Watanabe, 2008), who report that two distinct illiquidity states exist, while Acharya et al. (2013) find a similar result for the US bond market. To sum up, we find that illiquidity time series should not be modelled using linear methods, since illiquidity shocks are more persistent than previously thought and their effects tend to last for some time. These results are also consistent with the notion of liquidity spirals (Brunnermeier \& Pedersen, 2009) and the dual channel theorised by Chordia et al. (2000). 


\subsection{Illiquidity betas}

Next, we carry out empirical tests using the L-CAPM model with regime-dependent risk betas. The means of estimated liquidity betas are reported in Table 6 . The four betas, $\beta_{1}, \beta_{2}, \beta_{3}$ and $\beta_{4}$ for each portfolio and for each country are calculated as per Eqs. (19)-(22) using the entire monthly time-series available for each market. Table 6 also reports the average betas, calculated using the residuals from each state and the regime-dependent variance. We also report the average expected illiquidity cost, $E\left(c_{p}\right)$, found as a probability-weighted expected illiquidity, obtained from the residuals of a two state MSM for each portfolio, and for each market.

We note the prevalence of positive signs of $\beta_{1}$ and $\beta_{2}$ and negative signs for $\beta_{3}$ and $\beta_{4}$. The only exceptions to this trend can be found for Spain $\left(\beta_{2}\right)$ and Belgium and Germany $\left(\beta_{3}\right)$. The large variation in magnitude from country to country is explained by the different probability-weighted variances within the denominator for each beta, which is itself country-specific. The signs of the betas are consistent with previous research (Acharya \& Pedersen, 2005).

One of the benefits of our conditional model, compared to prior work, is that we can closely assess the variation in market and liquidity risk conditional on each regime. In particular, the dynamics of conditional covariances can be further appreciated by analysing the betas calculated conditional on the high and low regimes. The $\beta_{1}{ }^{H}$ and $\beta_{1}{ }^{L}$ indicate the regime-dependent conditional covariances between portfolios and the market return. As expected, this is positive for almost all the countries and for all regimes, except for the bull state observed for Germany. A more interesting feature relates to covariance of portfolio and market returns being greater during bear markets rather than bull markets for all the countries.

Similar conclusions can be drawn with respect to the first measure of liquidity risk $\left(\beta_{2}{ }^{H}, \beta_{2}{ }^{L}\right)$, which captures commonality in liquidity. The positive sign is generally justified by the fact that investors want to be compensated for holding a security that becomes illiquid when the market also does so (Acharya \& Pedersen, 2005). We find that almost all our measures are positive, consistent with prior studies (Acharya \& Pedersen, 2005; Chordia et al., 2000). The important new insight from our analysis is that the level of covariance varies from country to country between high and low illiquidity. For instance, we observe greater commonality during periods of relatively low illiquidity for the majority of markets, except Germany. The difference between regimes is also relatively small for Germany and France, while considerably wider for peripheral economies, such as Belgium, Finland, Greece and Spain.

The third risk factor arises from covariation between portfolio returns and market illiquidity, $\left(\beta_{3}{ }^{H}, \beta_{3}{ }^{L}\right)$. The negative relationship can be explained by the fact that investors are willing to accept a lower expected return on securities, which have high returns when markets are illiquid. Previous evi- dence (Pástor \& Stambaugh, 2003) provides empirical support for this claim. Our findings build upon prior research, but they also add to better understanding of the underlying puzzle. We show that such covariation is also greater during periods of low illiquidity, providing further support to existing research. All countries except France indicate a relatively greater $\beta_{3}{ }^{L}$. Moreover, Germany is the only market with a positive covariance in both regimes. While unexpected, the effect on the German market is partly mitigated by the evidence related to expected illiquidity $\left(E\left(c_{p}\right)\right)$ being the highest compared to other countries.

The last effect arises owing to covariance between portfolio illiquidity and market returns. This risk accounts for the willingness of investors to accept lower returns when they need to sell an illiquid security if markets go down. We find that this effect is systematically greater during periods of bear market for all countries. We observe a negative relationship in bull markets and a positive relationship in bear markets, with the exception of Belgium. This evidence seems to suggest that investors accept lower expected returns on a security that is liquid in bull market, but higher expected returns on an illiquid security during a bear market. This is also consistent with Amihud and Mendelson (1986), who find a concave relationship between illiquidity and returns. Therefore, contemporaneous returns significantly drop for illiquid securities in phases of market downturns more than liquid securities, thus raising future expected returns.

\subsection{Tests on conditional L-CAPM}

Next, we investigate how risk betas affect returns. We follow the Fama and MacBeth (1973) second-step regression in an OLS framework, using the pre-estimated regime-dependent betas. Our point estimates coincide with those obtained in a GMM framework. ${ }^{8}$ We do this by running cross-sectional regressions for each month on our sample across the 25 illiquidity-sorted portfolios. Our model, described by Eq. (23) is:

$$
\begin{aligned}
E\left(r_{t}^{i}-r_{t}^{f}\right) & =\lambda_{t}^{0}\left[E\left(c_{t}^{i} \mid z_{t+1}\right) \operatorname{Pr}\left(z_{t+1}=1 \mid c_{t}^{M}\right)+\Delta E\left(c_{t}^{i} \mid z_{t+1}\right.\right. \\
+ & \lambda_{t}^{1}\left[\left(\beta_{i, I}^{1} \mid z_{t+1}\right) \operatorname{Pr}\left(z_{t+1}=1 \mid r_{t}^{M}\right)+\Delta \beta_{i}^{1} \operatorname{Pr}\left(z_{t+1}\right.\right. \\
+ & \lambda_{t}^{2}\left[\left(\beta_{i, I}^{2} \mid z_{t+1}\right) \operatorname{Pr}\left(z_{t+1}=1 \mid c_{t}^{M}\right)+\Delta \beta_{i}^{2} \operatorname{Pr}\left(z_{t+1}\right.\right. \\
+ & \lambda_{t}^{3}\left[\left(\beta_{i, I}^{3} \mid z_{t+1}\right) \operatorname{Pr}\left(z_{t+1}=1 \mid r_{t}^{M}\right)+\Delta \beta_{i}^{3} \operatorname{Pr}\left(z_{t+1}\right.\right. \\
+ & \lambda_{t}^{4}\left[\left(\beta_{i, I}^{4} \mid z_{t+1}\right) \operatorname{Pr}\left(z_{t+1}=1 \mid c_{t}^{M}\right)+\Delta \beta_{i}^{4} \operatorname{Pr}\left(z_{t+1}=\right.\right.
\end{aligned}
$$

In the spirit of the original paper (Acharya \& Pedersen, 2005), we estimate our model using several different specifications. These include a unique beta, calculated as $\beta^{\text {net }}=\beta_{1}+\beta_{2}-\beta_{3}-\beta_{4}$ and a unique liquidity beta in addition to the market risk beta, obtained as $\beta_{\text {Liq }}{ }^{\text {net }}=\beta_{2}-\beta_{3}-\beta_{4}$. In addition, we run all the models above by including an intercept, $\alpha$,

8 Our results using GMM are available upon request. 
Table 6

Properties of illiquidity betas.

\begin{tabular}{|c|c|c|c|c|c|c|c|}
\hline & Belgium & Finland & France & Germany & Greece & Italy & Spain \\
\hline$E\left(c_{p}\right)$ & 1.401 & -0.436 & 1.232 & 1.629 & 1.232 & -2.33 & -2.215 \\
\hline$\beta_{1}$ & 7.127 & 1.539 & 11.142 & 0.300 & 0.027 & 0.78 & 3.386 \\
\hline$\beta_{2}$ & 2.955 & 0.353 & 0.577 & 0.110 & 1.261 & 0.15 & -1.609 \\
\hline$\beta_{3}$ & 0.927 & -0.938 & -0.194 & 0.115 & -0.324 & -0.31 & -1.208 \\
\hline$\beta_{4}$ & -7.078 & -4.457 & -10.930 & -0.257 & -2.248 & -2.49 & -1.461 \\
\hline$\beta_{1}{ }^{H}$ & 2.877 & 1.125 & 8.790 & -0.131 & 0.004 & 0.32 & 0.581 \\
\hline$\beta_{1}^{L}$ & 30.483 & 3.096 & 12.086 & 2.561 & 2.446 & 1.97 & 5.079 \\
\hline$\beta_{2}^{H}$ & 0.777 & 0.239 & 0.335 & 0.100 & 1.236 & 0.43 & -1.898 \\
\hline$\beta_{2}^{L}$ & 2.273 & 1.954 & 0.338 & -0.057 & 2.132 & 1.29 & 5.177 \\
\hline$\beta_{3}{ }^{H}$ & -0.100 & -0.932 & -0.082 & 0.029 & -0.325 & -0.43 & -1.332 \\
\hline$\beta_{3}{ }^{L}$ & 1.068 & -0.002 & -0.298 & 0.052 & -0.194 & -0.31 & 3.790 \\
\hline$\beta_{4}{ }^{H}$ & -7.237 & -4.416 & -10.934 & -0.239 & -2.212 & -2.51 & -1.452 \\
\hline$\beta_{4}{ }^{L}$ & -0.970 & 2.912 & 2.809 & 0.209 & 1.872 & 2.49 & 1.507 \\
\hline
\end{tabular}

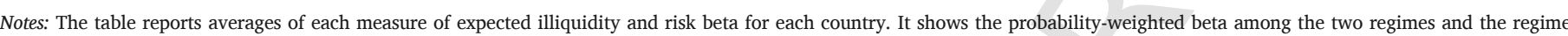
dependent beta.

suppressing the intercept, in order to better capture the marginal contribution of regime-dependent expected illiquidity, $E\left(c_{p}\right)$. While we report the general form of the model, represented by Eq. (23), our findings are robust to all the above specifications. Moreover, parameter estimates are obtained using heteroskedasticity robust standard errors.

In addition to the conditional version of the L-CAPM, this paper exploits a further benefit from the estimation of regime-dependent conditional covariances. We estimate a second model where risk premia are calculated for each regime-dependent measure, as in Eq. (24). We estimate also this model using a net beta for each regime, obtained as $\beta_{L}{ }^{\text {net }}=\beta_{1}{ }^{L}+\beta_{2}{ }^{L}-\beta_{3}{ }^{L}-\beta_{4}{ }^{L}$ for low regime betas and $\beta_{H}{ }^{\text {net }}=\beta_{1}{ }^{H}+\beta_{2}{ }^{H}-\beta_{3}{ }^{H}-\beta_{4}{ }^{H}$ for highregime betas. Similarly, we also distinguish between high and low net illiquidity betas. Although not reported for brevity, our results are robust to different specifications. Empirical results are reported in Table 7.

We find that almost all coefficients are significant, providing evidence that our conditional covariance L-CAPM does explain portfolio returns. Unexpected illiquidity has a negative and significant coefficient for France and Greece, while a positive and significant coefficient for the other markets. The negative relationship is theoretically consistent with previous studies that indicate a negative effect of unexpected illiquidity on contemporaneous stock returns (Amihud, 2002). In contrast, the positive coefficient for Italy and Spain is mitigated by the evidence that unexpected illiquidity is relatively lower than that for other Eurozone economies (see Table 6), partly explaining this counter intuitive result. It is more difficult to explain the positive coefficients for Belgium and Germany. A possible explanation is that Germany constitutes the biggest market in the Euro area, whereby unexpected illiquidity should result in a premium. Market risk premium is negative and significant for all markets, except Finland, although the marginal contribution in this market is very low. As noted by (Acharya \& Pedersen, 2005), a negative coefficient on $\beta_{1}$ does not necessarily imply a negative premium on market risk, but rather that liquidity risk may yield a greater premium. The negative premium on $\beta_{2}$, which captures commonality in liquidity, indicates that investors receive a negative risk premium when innovations in portfolio illiquidity are positively correlated with innovations in market illiquidity. In other terms, there is a lower premium when the unsystematic component of illiquidity shocks is diversified with illiquidity shocks in the market. The last two betas are highly significant for all the markets and positive for almost all of them. In other words, there is a premium for holding stocks that are illiquid during bull markets and for holding low performing stocks in liquid markets.

Panel B of Table 7 shows how risk premia vary with the market regime. We notice that the negative risk premium for market beta is generally greater in bull markets compared to bear markets. Similarly, there is a greater premium related to commonality in liquidity when markets are relatively more illiquid. While this evidence is theoretically sound, we also argue that lower returns due to a negative premium for commonality are also in line with the notion of flight to liquidity. Our positive and significant premium for $\beta_{3}$ highlighted in Panel A is also confirmed in the two-beta model shown in Panel B. This beta captures the premium for holding an illiquid stock when markets are bullish. For instance, it can be noted that during periods of bull markets, holding illiquid stocks provides greater premia for Finland, France and Greece, while holding liquid stocks in bear phases yields higher premia for the other markets. There is contrasting evidence for the last beta, which captures the sensitivity of stock returns to market illiquidity. While coefficients are highly significant, the premium has inconsistent signs across countries and across states. For instance, it indicates a positive (negative) premium for holding highly (poorly) performing stocks when market illiquidity decreases (increases). However, our sample includes three years following the expansionary monetary policy undertaken by the European Central Bank (ECB) to face the Eurodebt crisis. Therefore, our results are likely to reflect the higher returns that resulted from the boost in market liquidity through the quantitative easing. We also consider the possibility that not all of these risks are empirically relevant. Overall, our second model considerably improves the model fit, as is clear from a 
Table 7

Liquidity premium using OLS.

\begin{tabular}{|c|c|c|c|c|c|c|c|}
\hline & Belgium & Finland & France & Germany & Greece & Italy & Spain \\
\hline \multicolumn{8}{|c|}{ Panel A } \\
\hline \multirow[t]{2}{*}{$E\left(c_{p}\right)$} & $0.549^{* * * *}$ & 0.00173 & $-0.105^{* * *}$ & $0.335^{* * * *}$ & $-0.119^{* * *}$ & $0.0519 * * *$ & $0.0390^{* * * *}$ \\
\hline & $(32.76)$ & $(0.99)$ & $(-42.88)$ & (42.13) & $(-28.73)$ & $(48.59)$ & (29.45) \\
\hline \multirow[t]{2}{*}{$\beta_{1}$} & $-0.00876^{* * *}$ & $0.00323^{* * *}$ & $-0.0237^{* * *}$ & $-0.0394^{* * *}$ & $-0.0506^{* * *}$ & $-0.0628^{* * * *}$ & $-0.0342^{* * *}$ \\
\hline & $(-8.81)$ & (5.95) & $(-35.23)$ & $(-16.86)$ & $(-13.86)$ & $(-43.12)$ & $(-17.90)$ \\
\hline \multirow[t]{2}{*}{$\beta_{2}$} & $-0.103^{* * * *}$ & $-0.0376^{* * * *}$ & $-0.0251 * * *$ & $-0.732^{* * *}$ & $-0.114^{* * *}$ & $0.00913^{* * *}$ & $0.0128^{* * *}$ \\
\hline & $(-39.77)$ & $(-20.41)$ & $(-15.99)$ & $(-28.65)$ & $(-22.56)$ & $(23.41)$ & (26.09) \\
\hline \multirow{2}{*}{$\beta_{3}$} & $-0.110^{* * * *}$ & $0.0372^{* * *}$ & $-0.104^{* * *}$ & $1.463^{* * * *}$ & $0.258^{* * * *}$ & $0.378^{* * * *}$ & $0.0209^{* * *}$ \\
\hline & $(-7.94)$ & (20.15) & $(-18.38)$ & (41.26) & $(17.61)$ & $(64.84)$ & (16.23) \\
\hline \multirow{3}{*}{\multicolumn{8}{|c|}{$\begin{array}{l}R^{2} \\
\text { Panel B }\end{array}$}} \\
\hline & & & & & & & \\
\hline & & & & & & & \\
\hline \multirow[t]{2}{*}{$E\left(c_{p}\right)$} & $-0.0590^{* * *}$ & $0.00435 * * *$ & -0.00130 & $0.117^{* * * *}$ & $0.00996 * * *$ & $0.0289^{* * *}$ & $0.0221^{* * *}$ \\
\hline & $(-15.98)$ & $(3.36)$ & $(-0.86)$ & $(16.22)$ & $(3.52)$ & (37.04) & (25.83) \\
\hline \multirow[t]{2}{*}{$\beta_{1}{ }^{H}$} & $-0.00856^{* * *}$ & $0.00404 * * *$ & -0.000846 & $-0.0500^{* * * *}$ & $-0.0536^{\text {**** }}$ & $-0.0297^{* * *}$ & $-0.0290^{* * *}$ \\
\hline & $(-9.98)$ & $(5.08)$ & $(-0.93)$ & $(-2.82)$ & $(-13.53)$ & $(-20.83)$ & $(-25.21)$ \\
\hline \multirow[t]{2}{*}{$\beta_{1}{ }^{L}$} & $0.0450^{* * * *}$ & $-0.0375 * * *$ & $-0.0337^{* * * *}$ & $0.200 * * *$ & $-0.117^{* * *}$ & $-0.0439^{* * *}$ & $-0.0305^{* * *}$ \\
\hline & (33.88) & $(-20.51)$ & $(-57.32)$ & (42.79) & $(-30.31)$ & $(-37.89)$ & $(-23.04)$ \\
\hline$\beta_{2}{ }^{H}$ & $-0.203^{* * *}$ & $-0.0157^{* * * *}$ & $-0.0374^{* * *}$ & $0.134^{* * *}$ & $0.0201^{* * *}$ & $-0.00610^{* * * *}$ & $0.0122^{* * *}$ \\
\hline$\beta_{2}{ }^{L}$ & $(-26.74)$ & $(-25.21)$ & $(-10.64)$ & $(-3.78)$ & $(-28.91)$ & $(-55.13)$ & $(-22.17)$ \\
\hline \multirow[t]{2}{*}{$\beta_{3}{ }^{H}$} & $-0.656^{* * *}$ & -0.00124 & $-0.0230^{* * *}$ & $1.002^{* * *}$ & $-0.140^{* * * *}$ & $0.0869^{* * *}$ & $-0.0274^{* * *}$ \\
\hline & $(-15.49)$ & $(-0.65)$ & $(-3.65)$ & (25.74) & $(-8.76)$ & (19.76) & $(-17.44)$ \\
\hline \multirow[t]{2}{*}{$\beta_{3}{ }^{L}$} & $-0.343^{* * *}$ & $0.108^{* * *}$ & $0.282^{* * *}$ & $-0.474 * * *$ & $0.390^{* \star * *}$ & $-0.0372^{* * *}$ & $0.00344^{* * *}$ \\
\hline & $(-18.40)$ & (14.72) & (25.89) & $(-7.20)$ & (19.59) & $(-19.75)$ & $(4.53)$ \\
\hline \multirow[t]{2}{*}{$\beta_{4}{ }^{H}$} & $0.00970^{* * *}$ & $0.0208^{* * * k}$ & $0.00687^{* k * k}$ & $1.046^{* * *}$ & $0.0119^{* * *}$ & $-0.00203^{* * * k}$ & $0.0321^{* * *}$ \\
\hline & (10.36) & $(33.51)$ & $(45.34)$ & $(70.96)$ & (15.64) & $(-5.07)$ & $(41.21)$ \\
\hline \multirow[t]{2}{*}{$\beta_{4}{ }^{L}$} & $-0.0235^{* * * *}$ & $-0.0103^{* * *}$ & $-0.00835^{* * * *}$ & $0.717^{* * *}$ & $-0.00711^{* * * *}$ & $-0.00591^{* * *}$ & $-0.00608^{* * *}$ \\
\hline & $(-22.53)$ & $(-17.90)$ & $(-25.26)$ & (58.03) & $(-6.98)$ & $(-22.28)$ & $(-7.07)$ \\
\hline$R^{2}$ & 0.751 & 0.617 & 0.600 & 0.728 & 0.733 & 0.740 & 0.581 \\
\hline
\end{tabular}

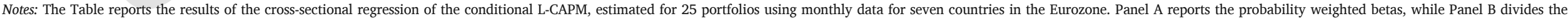
betas according to the regime. Parameters are estimated using heteroskedasticity-robust standard errors and t-statistics are reported in parentheses. The stars $(*)$ indicate the significance level: $10 \%(*), 5 \%(* *)$ and $1 \%(* * *)$. 
comparison of the $R^{2}$ measure in panels A and B. Moreover, while our $R^{2}$ results are smaller than those reported by Acharya and Pedersen (2005), their model is severely affected by collinearity problems, as they themselves and Lee (2011) point out.

We find ample evidence that liquidity is a priced risk factor in our conditional model, in contrast to previous work. For example, Lee (2011) finds only partial evidence that the three liquidity measures identified by Acharya and Pedersen (2005) are pricedrisk factors at a global level. On the other hand, Lee (2011) investigates a considerably greater sample that includes Eurozone countries and excludes the GFC, which may have played a major role in the pricing of liquidity risk. Lee (2011) employs an unconditional model, where liquidity is assumed to follow a linear evolution over time, while we provide empirical evidence that non-linear models have better ability to capture its time-varying behaviour. Thus, we argue that our model is better specified and the results are more robust.

\subsection{Robustness: panel evidence}

In this section, we report the robustness tests using panel data techniques. We estimate the conditional covariance L-CAPM using pooled OLS that mitigates the potential problems arising from the calculation of average parameters obtained using cross-sectional estimates. Table 8 reports the result. We observe that our estimates obtained with pooled cross-sectional regressions are consistent with those found using panel analysis. Coefficients are generally highly significant, with expected signs compared to those reported in Table 7. On the other hand, we note that the fit of the data reduces considerably using panel analysis.

In addition, commonality in liquidity is not a priced risk factor for the German market. We observe negative coefficients for all countries, except Spain $\left(\beta_{2}{ }^{H}\right)$ Greece reports a negative and significant coefficient for commonality only during periods of low illiquidity. We find that $\beta_{3}$ is not significant for Greece while highly significant for Germany. This risk factor represents the covariation between portfolio illiquidity and market returns. The positive and significant coefficient suggests that for the German market there is a positive premium for holding illiquid stocks when market prices go down. This positive premium may also constitute evidence of flight to liquidity, where investors prefer switching to core economies within the Eurozone, rather than peripheral markets. This evidence finds support also in the literature on contagion, where the financial channel constitutes a primary channel of spillover (Andrikopoulos et al., 2014; Smimou \& Khallouli, 2015). Lastly, we confirm

Table 8

Liquidity premium using panels.

\begin{tabular}{|c|c|c|c|c|c|c|c|}
\hline & Belgium & Finland & France & Germany & Greece & Italy & Spain \\
\hline \multicolumn{8}{|c|}{ Panel A } \\
\hline \multirow[t]{2}{*}{$E\left(c_{p}\right)$} & $0.562^{* * *}$ & 0.00173 & $-0.105^{* * *}$ & $0.335^{* * *}$ & $-0.119 * * *$ & $0.0519 * * *$ & $0.0388^{* k *}$ \\
\hline & $(0.0894)$ & (0.00849) & $(0.0121)$ & $(0.0217)$ & $(0.0201)$ & $(0.00375)$ & $(0.00613)$ \\
\hline \multirow[t]{2}{*}{$\beta_{1}$} & $-0.0101^{*}$ & 0.00323 & $-0.0237^{* * *}$ & $-0.0394 * * *$ & $-0.0506^{* * *}$ & $-0.0628^{* * *}$ & $-0.0346^{* * *}$ \\
\hline & $(0.00526)$ & $(0.00303)$ & $(0.00326)$ & $(0.0127)$ & $(0.0187)$ & $(0.00861)$ & $(0.00956)$ \\
\hline \multirow[t]{2}{*}{$\beta_{2}$} & $-0.105^{* * *}$ & $-0.0376^{\text {*** }}$ & $-0.0251^{* * *}$ & $-0.732^{* * *}$ & $-0.114^{* * *}$ & $0.00913^{* * *}$ & $0.0129 * * *$ \\
\hline & $(0.0140)$ & $(0.00820)$ & $(0.00935)$ & $(0.151)$ & $(0.0222)$ & $(0.00262)$ & $(0.00251)$ \\
\hline \multirow[t]{2}{*}{$\beta_{3}$} & -0.0961 & $0.0372^{* * *}$ & $-0.104^{* * *}$ & $1.463^{* * *}$ & $0.258^{* * *}$ & $0.378^{* * *}$ & $0.0206^{* * *}$ \\
\hline & $(0.0628)$ & $(0.00889)$ & $(0.0306)$ & $(0.186)$ & $(0.0787)$ & $(0.0239)$ & $(0.00692)$ \\
\hline \multirow[t]{2}{*}{$\beta_{4}$} & $0.0120^{* *}$ & $0.0315^{* k *}$ & $0.00839^{* * *}$ & $0.186^{* * *}$ & $0.0498^{* * *}$ & 0.00382 & $0.0288^{* * *}$ \\
\hline & $(0.00529)$ & $(0.00217)$ & $(0.000540)$ & $(0.0642)$ & $(0.00512)$ & $(0.00291)$ & $(0.00481)$ \\
\hline$R^{2}$ & 0.032 & 0.033 & 0.086 & 0.081 & 0.095 & 0.179 & 0.044 \\
\hline \multicolumn{8}{|c|}{ Panel B } \\
\hline \multirow[t]{2}{*}{$E\left(c_{p}\right)$} & $-0.0630 * * *$ & 0.00435 & -0.00130 & $0.117^{* * *}$ & 0.00996 & $0.0289 * * *$ & $0.0221^{k * *}$ \\
\hline & $(0.0213)$ & $(0.00643)$ & $(0.00793)$ & $(0.0237)$ & $(0.0129)$ & $(0.00360)$ & $(0.00380)$ \\
\hline \multirow[t]{2}{*}{$\beta_{1}{ }^{H}$} & $-0.0102^{* *}$ & 0.00404 & -0.000846 & -0.0500 & $-0.0536^{* * *}$ & $-0.0297^{* * *}$ & $-0.0292^{* * *}$ \\
\hline & $(0.00457)$ & $(0.00456)$ & $(0.00457)$ & $(0.114)$ & $(0.0202)$ & $(0.00931)$ & $(0.00589)$ \\
\hline \multirow[t]{2}{*}{$\beta_{1}{ }^{L}$} & $0.0472^{* * *}$ & $-0.0375^{* * *}$ & $-0.0337^{* * *}$ & $0.200^{* * *}$ & $-0.117^{* * *}$ & $-0.0439 * * *$ & $-0.0312^{* * *}$ \\
\hline & $(0.00724)$ & $(0.00855)$ & $(0.00292)$ & $(0.0238)$ & $(0.0190)$ & $(0.00681)$ & $(0.00670)$ \\
\hline \multirow[t]{2}{*}{$\beta_{2}{ }^{H}$} & $-0.210^{* * *}$ & -0.0157 & $-0.0374^{* * *}$ & 0.134 & 0.0201 & $-0.00610^{* *}$ & $0.0121^{* * *}$ \\
\hline & $(0.0319)$ & $(0.00955)$ & $(0.0111)$ & $(0.0971)$ & $(0.0155)$ & $(0.00271)$ & $(0.00203)$ \\
\hline \multirow[t]{2}{*}{$\beta_{2}{ }^{L}$} & $-0.0432^{* * *}$ & $-0.0245^{* * *}$ & $-0.0261^{* *}$ & -0.0956 & $-0.132 * * *$ & $-0.130^{* * *}$ & $-0.0191^{* * *}$ \\
\hline & $(0.00765)$ & $(0.00504)$ & $(0.0128)$ & $(0.166)$ & $(0.0208)$ & $(0.0101)$ & $(0.00459)$ \\
\hline \multirow[t]{2}{*}{$\beta_{3}{ }^{H}$} & $-0.727^{* * *}$ & -0.00124 & -0.0230 & $1.002^{* * *}$ & -0.140 & $0.0869^{* * *}$ & $-0.0268^{* * *}$ \\
\hline & $(0.211)$ & $(0.0101)$ & $(0.0341)$ & $(0.249)$ & $(0.0903)$ & $(0.0311)$ & $(0.00816)$ \\
\hline \multirow[t]{2}{*}{$\beta_{3}{ }^{L}$} & $-0.350^{* * *}$ & $0.108^{* * *}$ & $0.282^{* * *}$ & -0.474 & $0.390 * * *$ & $-0.0372^{* * *}$ & 0.00308 \\
\hline & $(0.0979)$ & $(0.0379)$ & $(0.0511)$ & $(0.376)$ & $(0.0972)$ & $(0.0136)$ & $(0.00406)$ \\
\hline \multirow[t]{2}{*}{$\beta_{4}{ }^{H}$} & $0.00846^{*}$ & $0.0208^{* k *}$ & $0.00687^{* * *}$ & $1.046^{* * *}$ & $0.0119 * *$ & -0.00203 & $0.0319^{* * *}$ \\
\hline & $(0.00472)$ & $(0.00268)$ & $(0.000480)$ & $(0.0892)$ & $(0.00529)$ & $(0.00331)$ & $(0.00403)$ \\
\hline \multirow[t]{2}{*}{$\beta_{4}{ }^{L}$} & $-0.0235^{* * *}$ & $-0.0103^{* * * *}$ & $-0.00835^{* * *}$ & $0.717^{* k *}$ & -0.00711 & $-0.00591^{* * *}$ & -0.00570 \\
\hline & $(0.00575)$ & $(0.00292)$ & $(0.00159)$ & $(0.0806)$ & $(0.00558)$ & $(0.00187)$ & $(0.00484)$ \\
\hline$R^{2}$ & 0.082 & 0.054 & 0.110 & 0.126 & 0.112 & 0.229 & 0.054 \\
\hline
\end{tabular}

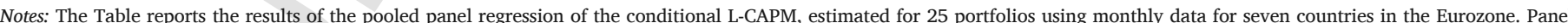

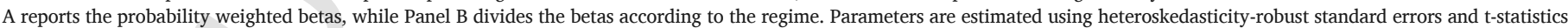
are reported in parentheses. The stars $\left(^{*}\right)$ indicate the significance level: $10 \%\left({ }^{*}\right), 5 \%(* *)$ and $1 \%(* * *)$. 
our prior findings with regards to $\beta_{4}$. While almost all the estimated parameters are highly significant, their sign varies from country to country and risk premia tends to cancel out between high and low regimes. As a further robustness test, we repeat our OLS, GMM and panel estimation with an annual frequency. Results, not included for brevity, confirm our findings using monthly data.

\section{Conclusions, implications and future research}

This paper investigates stock market illiquidity, its time-varying characteristics and the implications of pricing of illiquidity risk for a set of Eurozone countries for the period 1990-2018. Prior work frequently employs autoregressive (AR) processes to estimate time-varying illiquidity, but these techniques model innovations as temporary as well as Gaussian distributed (see, e.g., Amihud, 2002; Foran \& Hutchinson, 2014; Korajczyk \& Sadka, 2008), which may not be the case empirically. Recent market events, such as the global financial crisis of 2007-2009 and the subsequent Eurodebt crisis have shown that the effects of an illiquidity shock persists for longer periods. Therefore, AR processes result inappropriate in explaining the effects of sudden and pervasive illiquidity peaks and drops.

Using a non-linear approach based on Markov regime switching (MRS) models, we are able to capture the features of persistence of shocks. Our methodology overcomes the significant econometric limitations of AR processes owing to highly restrictive and unrealistic assumptions, and we contend that non-linear models are more appropriate within our analytical context. By using MRS models, we are able to determine distinct illiquidity states and we find that illiquidity shocks are persistent. Each illiquidity state is identified by the switching intercept of a two-state MRS model. Our estimated matrix of transition probabilities indicates a very low probability of switching between regimes. Thus, our methodological contribution is in line with related work (Brunnermeier \& Pedersen, 2009) which finds that the interaction between market and funding liquidity results in persistent liquidity spirals.

Our second contribution relates to the effects of persistent illiquidity states on the pricing of illiquidity risk within the cross-section of stock returns. We develop a liquidity-adjusted capital asset pricing model (L-CAPM), which account for time-varying risk sensitivities and extend previous unconditional models. We combine MRS and L-CAPM to estimate regime-dependent conditional covariances of returns and illiquidity innovations. While previous attempts combining MSM models and liquidity do exist, our paper is the first to construct and estimate illiquidity risk betas based on regime-dependent innovations in returns and illiquidity. We find strong evidence of pricing of illiquidity risk, using a probability weighted average of our regime-dependent conditional covariances and we extend previous attempts to include liquidity risk in a standard pricing model. Our results are in line with previous studies in terms of pricing of the different sources of liquidity risk. However, we provide further evidence showing that risk premia vary across regimes and each factor is priced differently between the two states, by splitting the risk premia in high and low regimes for each factor. Our analysis further extends previous work on the L-CAPM by showing that investors' risk aversion changes with the state of the market, both in terms of returns and illiquidity. This finding provides new evidence also with respect to time-varying illiquidity risk premia and extend the recent evidence of time-varying market risk premia (e.g., see Vendrame et al., 2018). We find that our results are robust to alternative estimation techniques and model specifications.

Our findings provide important implications for both academics and investors in wake of the outcomes of the 2007-2009 global financial crisis. Researchers can learn from the growing use of non-linear models in the asset pricing literature and extend empirical models beyond liquidity or market returns. Moreover, the evidence of persistent periods of high and low illiquidity that similarly to bull and bear cycles characterise financial markets constitute an important starting point to further investigate the characteristics of liquidity. Likewise, investors can potentially implement portfolio diversification strategies that better account for illiquidity shocks. In particular, portfolio optimization can be better achieved by taking into account the sensitivity of stocks to the different sources of illiquidity risk and the variation over time of liquidity risk premia, conditional on the prevailing regime in the market.

\section{Appendix A. Supplementary data}

Supplementary data to this article can be found online at https:// doi.org/10.1016/j.irfa.2019.05.002.

\section{References}

Acharya, V.V., Amihud, Y., Bharath, S.T., 2013. Liquidity risk of corporate bond returns: Conditional approach. Journal of Financial Economics 110 (2), 358-386.

Acharya, V.V., Pedersen, L.H., 2005. Asset pricing with liquidity risk. Journal of Financial Economics 77 (2), 375-410.

Al Janabi, M.A., Hernandez, J.A., Berger, T., Nguyen, D.K., 2017. Multivariate dependence and portfolio optimization algorithms under illiquid market scenarios. European Journal of Operational Research (3), 1121-1131.

Amihud, Y., 2002. Illiquidity and stock returns: Cross-section and time-series effects. Journal of Financial Markets 5 (1), 31-56.

Amihud, Y., Hameed, A., Kang, W., Zhang, H., 2015. The illiquidity premium: International evidence. Journal of Financial Economics (2), 350.

Amihud, Y., Mendelson, H., 1986. Asset pricing and the bid-ask spread. Journal of Financial Economics 17 (2), 223-249.

Amihud, Y., Mendelson, H., Wood, R., 1990. Liquidity and the 1987 stock market crash. Journal of Portfolio Management 65-69.

Andrews, D.W., 1993. Tests for parameter instability and structural change with unknown change point. Econometrica: Journal of the Econometric Society 821-856.

Andrikopoulos, A., Angelidis, T., Skintzi, V., 2014. Illiquidity, return and risk in g7 stock markets: Interdependencies and spillovers. International Review of Financial Analysis 35, 118-127.

Billio, M., Pelizzon, L., 2000. Value-at-risk: A multivariate switching regime approach. Journal of Empirical Finance 7 (5), 531-554. 
Bollerslev, T., 1986. Generalized autoregressive conditional heteroskedasticity. Journal of Econometrics 31 (3), 307-327.

Brockman, P., Chung, D.Y., Pérignon, C., 2009. Commonality in liquidity: A global perspective. Journal of Financial and Quantitative Analysis 44 (4), 851-882.

Brunnermeier, M.K., Pedersen, L.H., 2009. Market liquidity and funding liquidity. The Review of Financial Studies 22 (6), 2201-2238.

Chordia, T., Roll, R., Subrahmanyam, A., 2000. Commonality in liquidity. Journal of Financial Economics 56 (1), 3-28.

Dickey, D.A., Fuller, W.A., 1981. Likelihood ratio statistics for autoregressive time series with a unit root. Econometrica: Journal of the Econometric Society 1057-1072.

Fama, E.F., French, K.R., 1993. Common risk factors in the returns on stocks and bonds. Journal of Financial Economics 33 (1), 3-56.

Fama, E.F., MacBeth, J.D., 1973. Risk, return, and equilibrium: Empirical tests. Journal of Political Economy 81 (3), 607-636.

Ferreira, P., 2018. Efficiency or speculation? A time-varying analysis of European sovereign debt. Physica A: Statistical Mechanics and its Applications 490, 1295-1308.

Ferreira, P., Dionísio, A., Guedes, E.F., Zebende, G.F., 2018. A sliding windows approach to analyse the evolution of bank shares in the European Union. Physica A: Statistical Mechanics and its Applications 490, 1355-1367.

Ferreira, P., Kristoufek, L., 2017. What is new about covered interest parity condition in the European Union? Evidence from fractal cross-correlation regressions. Physica A: Statistical Mechanics and its Applications 486, 554-566.

Foran, J., Hutchinson, M. C. \& O'Sullivan, N. (2014), 'The asset pricing effects of UK market liquidity shocks: Evidence from tick data', International Review of Financial Analysis 32, 85-94.

Foran, J., Hutchinson, M. C. \& O'Sullivan, N. (2015), 'Liquidity commonality and pricing in UK equities', Research in International Business and Finance 34, 281-293.

Forbes, K.J., Rigobon, R., 2002. No contagion, only interdependence: Measuring stock market comovements. The Journal of Finance (5), 2223-2261.

Garcia, R., Perron, P., 1996. An analysis of the real interest rate under regime shifts. The Review of Economics and Statistics (1), 111-125.

Goyenko, R.Y., Holden, C.W., Trzcinka, C.A., 2009. Do liquidity measures measure liquidity?. Journal of Financial Economics (2), 153-181.

Guidolin, M., 2011. Markov switching in portfolio choice and asset pricing models: A survey. Vol. 27, Emerald Group Publishing Limited, 87-178, part 2.

Hamilton, J.D., 1989. A new approach to the economic analysis of nonstationary time series and the business cycle. Econometrica (2), 357-384.

He, Z., Kryzanowski, L., 2006. The cross section of expected returns and amortized spreads.
Pacific Basin Financial Markets and Policies 9 (04), 597-638.

Ince, O.S., Porter, R.B., 2006. Individual equity return data from Thomson datastream: Handle with care. Journal of Financial Research 29 (4), 463-479.

Jacoby, G., Fowler, D.J., Gottesman, A.A., 2000. The capital asset pricing model and the liquidity effect: A theoretical approach. Journal of Financial Markets 3 (1), 69-81.

Kim, C.-J., Morley, J.C., Nelson, C.R., 2004. Is there a positive relationship between stock market volatility and the equity premium?. Journal of Money, Credit, and Banking 36 (3), 339-360.

Korajczyk, R.A., Sadka, R., 2008. Pricing the commonality across alternative measures of liquidity. Journal of Financial Economics (1), 45-72.

Kwiatkowski, D., Phillips, P.C., Schmidt, P., Shin, Y., 1992. Testing the null hypothesis of stationarity against the alternative of a unit root: How sure are we that economic time series have a unit root?. Journal of Econometrics 54 (1-3), 159-178.

Kyle, A.S., 1985. Continuous auctions and insider trading. Econometrica 53 (6), 1315-1335.

Lee, K.-H., 2011. The world price of liquidity risk. Journal of Financial Economics 99 (1), $136-161$.

Lee, J., Strazicich, M.C., 2003. Minimum Lagrange multiplier unit root test with two structural breaks. The Review of Economics and Statistics 85 (4), 1082-1089.

Liu, W., 2006. A liquidity-augmented capital asset pricing model. Journal of Financial Economics 82 (3), 631-671.

Liu, W., Luo, D., Zhao, H., 2016. Transaction costs, liquidity risk, and the CCAPM. Journal of Banking \& Finance 63, 126-145.

Minović, J., Živković, B., 2014. Capm augmented with liquidity and size premium in the Croatian stock market. Economic Research-Ekonomska istraživanja 27 (1), 191-206.

Papavassiliou, V.G., 2013. A new method for estimating liquidity risk: Insights from a liquidity-adjusted capm framework. Journal of International Financial Markets, Institutions and Money 24, 184-197.

Pástor, L., Stambaugh, R.F., 2003. Liquidity risk and expected stock returns. Journal of Political Economy 111 (3), 642-685.

Roll, R., 1988. The international crash of October 1987. Financial Analysts Journal 44 (5), 19-35.

Smimou, K., Khallouli, W., 2015. On the intensity of liquidity spillovers in the Eurozone. International Review of Financial Analysis

Vendrame, V., Guermat, C., Tucker, J., 2018. A conditional regime switching capm. International Review of Financial Analysis 1-11.

Vu, V., Chai, D., Do, V., 2015. Empirical tests on the liquidity-adjusted capital asset pricing model. Pacific-Basin Finance Journal 73-89.

Watanabe, A., Watanabe, M., 2008. Time-varying liquidity risk and the cross section of stock returns. The Review of Financial Studies (6), 2449-2486.

Zivot, E., Andrews, D.W.K., 1992. Further evidence on the great crash, the oil-price shock, and the unit-root hypothesis. Journal of Business \& Economic Statistics 10 (3), 251-270. 